\title{
Factors affecting the development and dynamics of hypoxia in a large shallow stratified lake: Hourly to seasonal patterns
}

\author{
Damien Bouffard, ${ }^{1}$ Josef Daniel Ackerman, ${ }^{2}$ and Leon Boegman ${ }^{1}$ \\ Received 2 October 2012; revised 25 February 2013; accepted 8 April 2013; published 8 May 2013.
}

[1] The examination of hypoxia in the hypolimnion of large lakes traditionally focuses on the assessment of its spatial and temporal extent and its effect on water quality. In Lake Erie, hypoxia typically occurs between July and October in the central basin; however, there is considerable interannual variability both spatially and temporally. The processes driving this interannual variability as well as the small-scale time variation in oxygen depletion (e.g., -0.7 to $+0.3 \mathrm{mg} \mathrm{L}^{-1} \mathrm{~d}^{-1}$ ) were examined in a field study conducted in the western part of the central basin of Lake Erie in 2008 and 2009. Data were obtained from a spatial array of moorings as well as sampling cruises that examined the physical and biological conditions needed to investigate the dynamics of the oxygen depletion and create a vertical oxygen budget. The flux of oxygen through the thermocline to the hypolimnion was a significant source of oxygen equivalent to $\sim 18 \%$ of the total oxygen depletion in the hypolimnion over the stratified period. The total oxygen depletion in the hypolimnion was due to equivalent amounts of hypolimnetic oxygen demand due to respiration in the water column and flux of oxygen to the bottom due to sediment oxygen demand. This latter finding was strongly dependent on hypolimnion thickness in Lake Erie, which also appeared to be an important parameter driving the rate of oxygen depletion by controlling the vertical volumetric fluxes and hence the competition between vertical flux and community respiration in the hypolimnion of shallow lakes.

Citation: Bouffard, D., J. D. Ackerman, and L. Boegman (2013), Factors affecting the development and dynamics of hypoxia in a large shallow stratified lake: Hourly to seasonal patterns, Water Resour. Res., 49, 2380-2394, doi:10.1002/wrcr.20241.

\section{Introduction}

[2] Hypoxia or a dissolved oxygen (DO) concentration lower than $2 \mathrm{mg} \mathrm{L}^{-1}$ is a major concern for the coastal ocean and enclosed basins [Diaz and Rosenberg, 2008] and can be attributed to biological and biogeochemical activity in the water column and in the sediments [Rabalais et al., 2002]. Whereas the former location is linked directly to the nutrient level in the water column (i.e., eutrophication), the flux of oxygen from the water to the sediment in the latter, depends on the biochemical properties of the sediment as well as the dynamics of the basin; it is, therefore, subject to short-time fluctuations [Hondzo, 1998]. The competition between the two oxygen sinks becomes more complex during the summer when the water becomes thermally stratified. At this time, the epilimnion is close to DO saturation due to oxygen flux at the surface, photosynthetic activity in the euphotic zone, and wind induced mixing; however, the hypolimnion becomes isolated from these oxygen sources

\footnotetext{
${ }^{1}$ Environmental Fluid Dynamics Laboratory, Department of Civil Engineering, Queen's University, Kingston, Ontario, Canada.

${ }^{2}$ Physical Ecology Laboratory, Department of Integrative Biology, University of Guelph, Guelph, Ontario, Canada.

Corresponding author: J. D. Ackerman, Physical Ecology Laboratory, Department of Integrative Biology, University of Guelph, Guelph, Ontario, Canada N1G 2W1. (ackerman@uoguelph.ca)

because of the thermocline, which strongly reduces the vertical flux of DO, and can become hypoxic because of the hypolimnetic oxygen demand (HOD) and the sediment oxygen demand (SOD) [Charlton, 1980]. From a hydrodynamic perspective, the relative contribution of SOD to the hypolimnetic oxygen depletion rate will be dependent on the location of the thermocline or the thickness of the hypolimnion, which would likely affect the relative contribution of these two sinks of DO (i.e., HOD and SOD) and hence the development and dynamics of hypoxia.

[3] Lake Erie, which is the shallowest and the most populated watershed of the Laurentian Great Lakes, provides an excellent opportunity to examine hypoxia. The lake varies in physical structure and contains three basins, which experience different levels of hypoxia. Specifically, the western basin is shallow (mean depth, $h=7 \mathrm{~m}$ ), eutrophic, and stratifies intermittently on a diurnal basis, but may experience severe hypoxia for a few days annually [Ackerman et al., 2001; Loewen et al., 2007]. The central basin is much larger and deeper $(h=19 \mathrm{~m})$, is mesotrophic, stratifies during the summer, and has a long history of severe hypoxia and anoxia affecting lake biota [Mortimer, 1987]. The eastern basin is relatively small and deep $(h=28.5 \mathrm{~m})$, oligotrophic, and stratifies in summer with oxygen conditions changing little since 1929 [Charlton, 1987].

[4] Lake Erie has a long history of water quality problems, including severe hypoxia [Edwards et al., 2005; Matisoff and Ciborowski, 2005; Conroy et al., 2010]. Phosphorus loading was first identified as a major factor 
responsible for the eutrophication of the lake, which resulted in the enrichment of hypolimnetic waters by decomposing phytoplankton leading to hypoxia [Mortimer, 1987]. Although point-source phosphorus reduction measures have been implemented since 1972, delays in the improvement of the water quality, including parameters such as DO in the hypolimnion, have been observed, and long-term measurements in Lake Erie indicated a stronger interannual variability than in other lakes, which may obscure improvements in water quality [Matisoff and Ciborowski, 2005]. This finding appears to contradict the traditional relationship between the annual phosphorus loading and the parameterized minimum DO concentration at the end of the summer [Chapra and Canale, 1991]. Recently, however, Matzinger et al. [2010] suggested that there may be a lag of several decades between the decrease in nutrient loading and the improvement to water quality in shallow lakes due to the biogeochemical history of the sediments involved in the consumption of DO (i.e., SOD). Changes in the water level, invasive species, and/or climate change are commonly cited to explain this variability [Ackerman et al., 2001; Hawley et al., 2006; Conroy et al., 2010]; however, hydrodynamic processes may also play an important role [Rao et al., 2008]. This paradox is a main motivation for this study on hypolimnetic oxygen depletion in Lake Erie.

[5] From a hydrodynamic perspective, it is important to distinguish between the seasonal circulation and the hourly currents in central Lake Erie as these will affect the transport and fate of scalars like DO [Mortimer, 1987]. The large-scale circulation involves a mean flow directed toward the east, which is affected by a two-gyre circulation pattern in the central basin (a counterclockwise gyre in the western part and a clockwise gyre in the eastern part) [Saylor and Miller, 1987; Beletsky et al., 1999]. The hourly circulation is primarily due to surface seiche (barotropic motion that imposes an oscillatory flow with a period of $\sim 15 \mathrm{~h}$ ) and near-inertial internal Poincaré waves (baroclinic motion that leads to an oscillation in the thermocline depth with a period of $\sim 17 \mathrm{~h}$, as well as a clockwise rotating current with elliptical track a few kilometers in diameter with opposite direction in the epilimnion and hypolimnion) [Mortimer, 1987; Rao et al., 2008; Bouffard et al., 2012]. In addition to affecting the lake bed, Poincaré wave currents also induces a strong shear in the thermocline [Bouffard et al., 2012]. Including physical processes into the oxygen budget requires an examination of short subdaily time scales. From a management perspective, however, the rate of oxygen depletion should be investigated at seasonal time scales. The present study, therefore, examines the development and dynamics of hypoxia in Lake Erie from seasonal to hourly time scales. More precisely, at large time scales, the development of the DO conditions is related to the external forcing (e.g., wind and heat flux), the water level, the temperature and stratification, the flow, and the organic content in the water. At smaller time scales, the dynamics of DO depletion are related to the vertical fluxes through the thermocline and through the sediment. We ultimately link the different approaches and extend our results by discussing the effect in terms of climate change and by comparing our results to other lakes. An investigation of these processes should inform the mechanistic basis of hypoxia, as well as aid in water quality management.

\section{Methods}

\subsection{Field Site}

[6] Nine stations along the main east-west axis of Lake Erie were equipped with moorings and regularly sampled for water quality and turbulence data from the Canadian Coast Guard Ship Limnos (Environment Canada) and the Ontario Ministry of National Resources Ship Keenosay during the summers of 2008 and 2009 (Figure 1). This approach provided a high-resolution (HR) grid of spatial and temporal measurement in the western region of the central basin (Stations 1227, 1228, 341, and 1231 with Stations 1229 and 1230 positioned north and south of Station 341 , respectively), in addition to measurements recorded in each basin (Stations 357, 84, and 452 from west to east, respectively). Details of the instruments are provided in Table 1.

[7] External forcing (i.e., wind speed and direction as well as heat flux) was evaluated using data obtained from a Meteorological buoy located at Stations 341. Heat flux was calculated using the Sea-Mat MATLAB toolbox (woodshole.er.usgs.gov/operations/sea-mat/), and wind data were corrected to $10 \mathrm{~m}$ height assuming a logarithmic velocity profile. Water level data were obtained from the Buffalo and Toledo water level stations (U.S. National Oceanic and Atmospheric Administration) located at opposite ends of the lake. These data were also used to measure the change in the water level over the last century.

[8] A number of parameters were assessed in the hypolimnion at each station. The thermocline depth, $h_{t}$, and thickness, $\Delta z$, were calculated using moored thermistor chains (TR 1050 and 1060 RBR, Ottawa, Canada). The thermocline was defined by the maximum value of the Brunt-Väisälä, or buoyancy, frequency, $N_{\max }^{2}$, and the hypolimnion thickness, $H$, was defined as the distance from the lake bed to the "foot" of the thermocline determined as $N^{2}<5 \times 10^{-5} \mathrm{~s}^{-2}$. Here, $N^{2}=-(g / \rho)(\partial \rho / \partial z)$, where $g$ is the gravitational acceleration, $\rho$ is the fluid density, and $z$ is

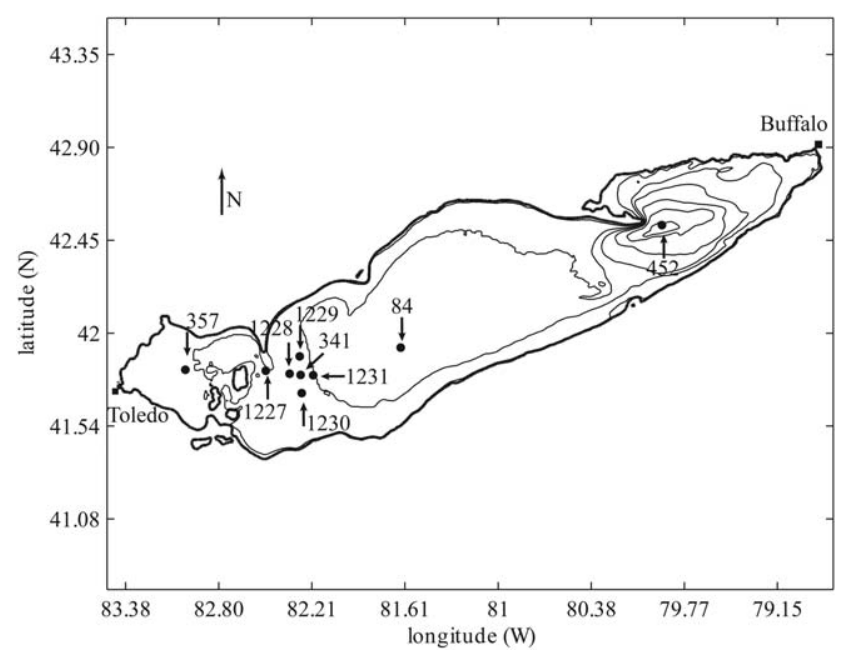

Figure 1. Map of Lake Erie showing the placement of the mooring and sampling stations (from west to east: Stations $357,1227,1228,1229,1230,341,1231,84$, and 452). 
Table 1. Station Locations and Instruments Used in the Study ${ }^{\mathrm{a}}$

\begin{tabular}{|c|c|c|c|c|c|}
\hline Station & Latitude/Longitude & Depth (m) & $\begin{array}{l}\text { Instruments } \\
\text { (Manufacturer) }\end{array}$ & Sampling Period & Height Above Bottom B-[X] (m) \\
\hline \multirow[t]{2}{*}{357} & $41^{\circ} 49^{\prime} 51^{\prime \prime} / 82^{\circ} 58^{\prime} 16^{\prime \prime}$ & 10.5 & DO (RBR) & $10 \mathrm{~s}$ & [1] \\
\hline & & & TR (Tidbit; Onset) & $1 \mathrm{~h}$ & {$[1.5,3.5,5.5,7.5,9.5]$} \\
\hline \multirow[t]{3}{*}{1227} & $41^{\circ} 48^{\prime} 35^{\prime \prime} / 82^{\circ} 30^{\prime} 13^{\prime \prime}$ & 11.4 & $\mathrm{DO}(\mathrm{YSI})$ & $1 \mathrm{~h}$ & [1] \\
\hline & & & TR (Tidbit) & $1 \mathrm{~h}$ & $\begin{array}{l}{[0.5,2.2,2.7,3.4,4.4,5.4,6.4,7.4,8.4,9.4} \\
\quad 10.4]\end{array}$ \\
\hline & & & ACDP (Sontek) & $1 \mathrm{~h}$ & [1] \\
\hline \multirow[t]{5}{*}{1228} & $41^{\circ} 47^{\prime} 41^{\prime \prime} / 82^{\circ} 21^{\prime} 17^{\prime \prime}$ & 14.4 & Sediment trap & & {$[1,5]$} \\
\hline & & & DO (YSI) & $1 \mathrm{~h}$ & [1] \\
\hline & & & DO (RBR) & $10 \mathrm{~s}$ & {$[1,2,5]$} \\
\hline & & & TR (RBR) & $10 \mathrm{~s}$ & $\begin{array}{l}{[1,1.5,2,2.5,3,4,6,7.5,8.5,9.5,10.5,} \\
\quad 11.5,12.5,13.5]\end{array}$ \\
\hline & & & ADCP Down & $1 \mathrm{~s}$ & [5] \\
\hline \multirow[t]{7}{*}{341} & $41^{\circ} 47^{\prime} 33^{\prime \prime} / 82^{\circ} 16^{\prime} 57^{\prime \prime}$ & 17.5 & Sediment trap & & {$[1,5]$} \\
\hline & & & ADCP Up & $900 \mathrm{~s}$ & $\begin{array}{l}{[1.8] 1 \mathrm{~m} \text { bin bursting mode } 180 \mathrm{~s} \text { every } 900} \\
\mathrm{~s}\end{array}$ \\
\hline & & & HR ADCP Down & $1 \mathrm{~s}$ & $\begin{array}{l}\text { [1.8] } 3 \mathrm{~cm} \text { bin bursting mode } 180 \mathrm{~s} \text { every } \\
900 \mathrm{~s}\end{array}$ \\
\hline & & & Acoustic Doppler velocimeter & $0.0625 \mathrm{~s}$ & [1] bursting mode 5 min every $20 \mathrm{~min}$ \\
\hline & & & TR (RBR) & $10 \mathrm{~s}$ & $\begin{array}{l}{[0.5,0.75,1,1.6,2,2.5,33.5,4,5,8,9,10} \\
\quad 11,12,13,14,15.5,16.5]\end{array}$ \\
\hline & & & DO (RBR) & $10 \mathrm{~s}$ & {$[0.5,1,2,5]$} \\
\hline & & & $\mathrm{XR}(\mathrm{RBR} ; \mathrm{Chl} a)$ & $10 \mathrm{~s}$ & {$[1,5]$} \\
\hline \multirow[t]{5}{*}{1231} & $41^{\circ} 47^{\prime} 34^{\prime \prime} / 82^{\circ} 11^{\prime} 24^{\prime \prime}$ & 19.8 & Sediment trap & & {$[1,5]$} \\
\hline & & & TR (RBR) & $10 \mathrm{~s}$ & $\begin{array}{l}{[0.5,3.3,3.8,4.3,4.8,5.8,6.8,7.3,8.3,9.8} \\
\quad 10.8,11.8,12.8,13.8,14.8,15.8,16.8 \\
\quad 17.8,18.8]\end{array}$ \\
\hline & & & DO (RBR) & $10 \mathrm{~s}$ & {$[0.5,1,2,5]$} \\
\hline & & & DO (YSI) & $1 \mathrm{~h}$ & [1] \\
\hline & & & ADCP Down & $1 \mathrm{~h}$ & [8] \\
\hline 1229 & $41^{\circ} 52^{\prime} 09^{\prime \prime} / 82^{\circ} 19^{\prime} 33^{\prime \prime}$ & 16.3 & $\mathrm{DO}(\mathrm{YSI})$ & $1 \mathrm{~h}$ & [1] \\
\hline 1230 & $41^{\circ} 43^{\prime} 30^{\prime \prime} / 82^{\circ} 17^{\prime} 31^{\prime \prime}$ & 17.1 & $\mathrm{DO}$ (YSI) & $1 \mathrm{~h}$ & [1] \\
\hline 84 & $41^{\circ} 55^{\prime} 08^{\prime \prime} / 81^{\circ} 38^{\prime} 36^{\prime \prime}$ & 24.8 & TR (Tidbit) & $1 \mathrm{~h}$ & $\begin{array}{l}{[1.8,2.8,3.8,4.8,5.8,6.8,7.8,8.8,9.8,11.8,} \\
\quad 13.8,15.8,17.8,19.8,21.8,23.8]\end{array}$ \\
\hline 452 & $41^{\circ} 34^{\prime} 55^{\prime \prime} / 79^{\circ} 55^{\prime} 23^{\prime \prime}$ & 54.5 & $\begin{array}{l}\text { DO (RBR) } \\
\text { TR (Tidbit) }\end{array}$ & $\begin{array}{c}10 \mathrm{~s} \\
1 \mathrm{~h}\end{array}$ & 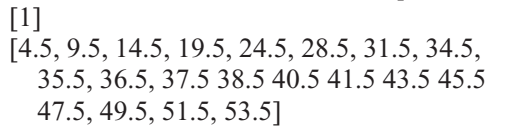 \\
\hline
\end{tabular}

${ }^{\mathrm{a} D O}$, dissolved oxygen; TR, temperature; ADCP, acoustic Doppler current profiler. See text for details.

the depth, was calculated using a cubic spline interpolation $(10 \mathrm{~cm})$ of the $1 \mathrm{~m}$ spaced thermistor data (Table 1$)$.

[9] Biologically relevant parameters such as DO and Chlorophyll $a(\mathrm{Chl} a)$ concentrations (DO 1050 and XR 420, respectively; RBR, Ottawa, Canada) were depthweight averaged in the hypolimnion as in Burns [1976]. Care was taken to correct the high-frequency DO data from biofouling even though the moorings were refurbished in July (day of year [doy] 210-214 in 2008 and 194-197 in 2009). At that time, the DO probes were placed in a fully oxygenated water container before and after cleaning the sensors. The difference, $\alpha$, between the two saturated measurements represented the contamination due to biofouling. The biofouling contamination was also assessed by comparing the average DO 2 days before and after the refurbishment and by taking into account the local depletion rate: $\overline{\mathrm{DO}}_{\text {before }}-\alpha \overline{\mathrm{DO}}_{\mathrm{after}}=\frac{\overline{\Delta \mathrm{DO}}}{\Delta t}$, where the overbar denotes a time average (i.e., 2 days). Once $\alpha$ (typically $\sim 0.3$ ) was corrected at the end of the time series, a squareroot fit was applied to correct the DO logger over time: $\mathrm{DO}(t)_{\text {corrected }}=\alpha\left(\sqrt{t / T_{\mathrm{all}}}+1\right)$, where $t$ is time and $T_{\text {all }}$ is the total moored period. The temporal correction was applied to all the RBR DO loggers and provided the best correlation to the lower frequency DO time series data obtained from instruments with an automatic cleaning system (YSI 6600; Yellow Springs, OH).

[10] The assessment of the spatial and temporal variability of the organic content of particles in the hypolimnion and in the bottom sediments was obtained as follows. In the water column, sediment traps at 1 and $5 \mathrm{~m}$ above the bottom (B-1 and B-5) were used to estimate the rate of sedimentation by measuring the mass collected between refurbishments (from doy 120 to 212). The organic content was obtained from the ash-free dry weights determined by the National Water Research Institute (Environment Canada; Charlton and Lean [1987]. The organic content of particles in the hypolimnion was obtained in a similar manner from the total suspended solids (TSS) analysis of 1- or 2-L water samples collected at B-1, B-2, and B-5 (during sampling cruises) filtered through precombusted glass-fiber filters (AMD $\mathrm{GF} / \mathrm{F} ; 0.7 \mu \mathrm{m}$ nominal pore size). Bottom sediments were obtained by box cores at stations along the west-east transect (e.g., Stations 357, 1227, 1228, 341, 1231, and 87). A $7.5 \mathrm{~cm}$-diameter acrylic tube was used to obtain two sediment core profiles, which were separated 
into $0-1,1-2,2-3,3-5$, and $5-7 \mathrm{~cm}$ fractions $(0 \mathrm{~cm}=$ sediment water interface) and frozen. The organic content of the fractions was obtained from the ash-free dry weights.

[11] Water currents $(u$ and $v$ in the horizontal $x$ and $y$ directions, respectively) in the water column were monitored at Station 341 using an upward looking acoustic Doppler current profiler (ADCP, $600 \mathrm{kHz}$; Nortek, Boston, $\mathrm{MA})$ at B-1.8 $\mathrm{m}$ in $1 \mathrm{~m}$ bins. The bottom boundary layer was investigated using a HR pulse coherent ADCP (2 MHz HR ADCP; Nortek) recording velocity in $3 \mathrm{~cm}$ bins at 1 Hz. A downward-looking acoustic Doppler velocimeter (ADV) was mounted at B-1 $\mathrm{m}$ on the tripod (as in Lorke [2007]). The three other HR stations (Stations 1227, 1228, and 1231) were equipped with downward-looking ADCP at B-5 $\mathrm{m}$ above the lake bed recording the velocity profile close to the bottom. All stations were equipped with temperature chain loggers at $1 \mathrm{~m}$ minimum resolution over the water column (Table 1).

\subsection{Vertical Flux of DO}

[12] The instrument configuration at Station 341 (i.e., temperature chain and ADCP spanning the water column and a HR downward-looking ADCP focused on the bottom boundary layer) provided an opportunity to estimate oxygen flux through the thermocline and through the sedimentwater interface. A time series of Richardson number, $R i=\overline{N^{2}} /\left((\mathrm{d} u / \mathrm{d} x)^{2}+(\mathrm{d} v / \mathrm{d} y)^{2}\right)$, over $1 \mathrm{~m}$ bins was calculated to provide an indication of the dynamical stability of the stratified shear flow. The vertical diffusivity $\left(K_{z}\right)$ was calculated using [Lozovatsky et al., 2006],

$$
K_{z}=\frac{K_{o}}{\left(1+R i_{c}^{-1} R i\right)^{p} \operatorname{Pr}_{\mathrm{Tr}}},
$$

where $K_{o}$ represents the eddy diffusivity in the nonstratified case (a tunable parameter); $R i_{c}$ is the transition from nonturbulent to turbulent flow; $P r_{\mathrm{Tr}}$ is the turbulent Prandtl number defined as $\operatorname{Pr}_{\mathrm{Tr}}=1+R i_{b}^{-1} R i$, where $R i_{b}$ is the transition to when vertical mixing starts to be affected by stratification more significantly than the momentum flux; and $p=5 / 3$ is a constant. This parameterization was found to provide good agreement with the distribution of the $K_{z}$ estimated using a temperature microstructure profiler (SelfContained Autonomous Microstructure Profiler; Precision Measuring Engineering, CA, USA) during the water quality sampling cruise at Station 341 [Bouffard et al., 2012]. Their analysis enabled us to compare the results to the $R i$-based $K_{z}$ distribution in this study (Figure 2). We set $K_{o}=2 \times$ $10^{-4} \mathrm{~m}^{2} \mathrm{~s}^{-1}, R i_{c}=0.25$, and $R i_{b}=0.15$. It should be noted that $R i_{c}=0.1$ and $R i_{b}=0.05$ used here were higher than those values suggested in Lozovatsky et al. [2006] because our $1 \mathrm{~m}$ bins were larger than the typical overturning scale (typically similar to the Ozmidov scale, $L_{O}$ ) and large bins artificially increase $R i$ [Polzin, 1996].

[13] The oxygen flux through the thermocline $\left(F_{\mathrm{th}}\right)$

$$
F_{\text {th }}=K_{z} \frac{\mathrm{DO}_{e}-\mathrm{DO}}{\Delta z}
$$

was calculated assuming that the epilimnetic water was fully saturated in oxygen, $\mathrm{DO}_{e}$, which was observed in the

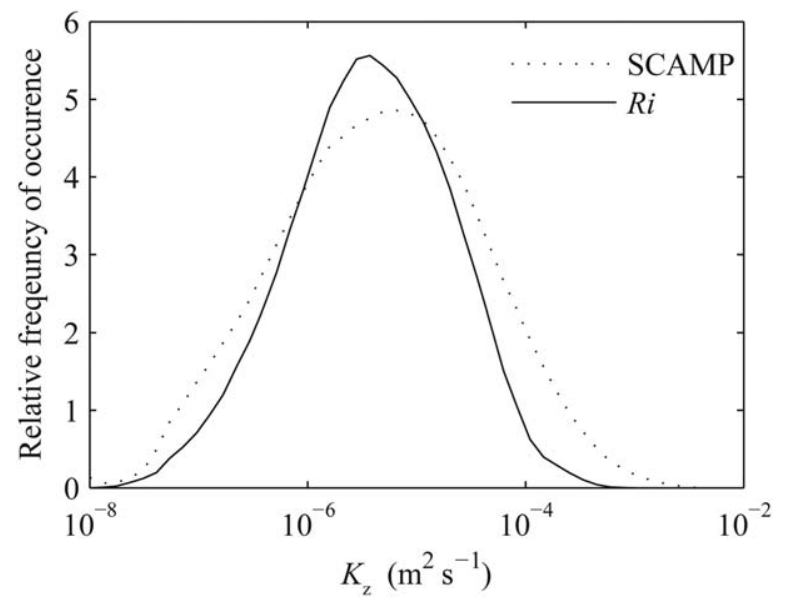

Figure 2. Frequency distribution of the vertical diffusivity, $K_{z}$, for Station 341 in 2008 and 2009. Only data with $N^{2}>5 \times 10^{-4} \mathrm{~s}^{-2}$ were selected. Method to estimate the diffusivity from the temperature microstructure profiler (Self-Contained Autonomous Microstructure Profiler) is explained in Bouffard et al. [2012].

instruments casts carried out during water quality cruises (data not shown). A positive flux indicates a transfer of oxygen from the epilimnion into the hypolimnion. The peak of oxygen usually observed at the top of the thermocline due to the Chl $a$ peak [Fee, 1976] was neglected, and therefore, the total flux was likely underestimated to a minor extent.

[14] The potential sinks of DO below the thermocline were the HOD (in $\mathrm{g} \mathrm{m}^{-3} \mathrm{~d}^{-1}$ ) and the SOD (in $\mathrm{g} \mathrm{m}^{-2} \mathrm{~d}^{-1}$ ). On a seasonal time scale, HOD and SOD were computed using an inversely proportional fit of the rate of oxygen depletion to the hypolimnion thickness $(H)$ given by

$$
\frac{\mathrm{dDO}}{\mathrm{d} t}=\frac{\mathrm{SOD}}{H}+\mathrm{HOD},
$$

with DO represented as the depth-averaged DO concentration in the hypolimnion. A more accurate estimate of the SOD time series was calculated using a mass transfer balance at the sediment-water interface. In this case, the vertical flux due to SOD is expressed as

$$
\mathrm{SOD}=\frac{D\left(\mathrm{DO}-\mathrm{DO}_{\mathrm{SWI}}\right)}{\delta_{\mathrm{DO}_{\mathrm{DBL}}}}
$$

where $D$ is the molecular diffusivity, $\delta_{\mathrm{DO}}$ is is the diffusive scalar boundary layer thickness, and $\mathrm{DO}_{\mathrm{SWI}}$ is the oxygen concentration at the sediment-water interface. The classical approach to determine $D / \delta_{\mathrm{DO}}$ 虫 to express it as a function of the friction velocity $u^{*}$, the Schmidt number $S c=\nu / D$, where $\nu$ is the kinematic viscosity, and the overlaying DO [Hondzo, 1998; Lorke et al., 2003],

$$
\frac{D}{\delta_{\mathrm{DO}_{\mathrm{DBL}}}}=0.0558 u_{*} S c^{-2 / 3},
$$

where $u^{*}$ is computed assuming steady flow and a logarithmic velocity profile [Hondzo, 1998]. Note that the 
Batchelor scale, $L_{B}=2 \pi\left(\nu D^{2} / \varepsilon\right)^{1 / 4}$, is sometimes used as a relevant length to scale $\delta_{\mathrm{DO}_{\mathrm{DBL}}}$ [Lorke et al., 2003] and thus characterize the smallest length scale of the turbulent scalar (DO) fluctuations. Given this condition, the rate of dissipation of turbulent kinetic energy, $\varepsilon=u_{*}^{3} / \kappa z$, was calculated using the HR ADCP and a first-order structure function method applied over the beam velocities [Wiles et al., 2006]. A robust-fit method was used to infer $u^{*}$ from the three acoustic beam dissipations profiles. Although the flow at the lake bed is not always best described with a logarithmic profile [Lorke et al., 2002], the diffusive boundary layer acts as a low-pass filter and is, therefore, more responsive to the small velocity fluctuations [Scalo et al., 2012].

[15] The concentration of oxygen at the sediment-water interface depends on the conditions in the water column and the rate of oxygen consumption in the sediment given by

$$
\frac{\partial \mathrm{DO}}{\partial t}=D_{s} \frac{\partial^{2} \mathrm{DO}}{\partial z^{2}}-\frac{R_{m} \mathrm{DO}}{K_{m}+\mathrm{DO}},
$$

where $D_{s}=0.64$ and $D$ is the diffusion coefficient of DO in the sediment. The maximum utilization rate $\left(R_{m}\right)$ and the half-saturation coefficient $\left(K_{m}\right)$ for DO measured at different locations in the central basin of Lake Erie in the summer of 2002 (i.e., $R_{m} \sim 110 \pm 40$ [mean \pm standard error] $\mathrm{mg} \mathrm{L}^{-1} \mathrm{~d}^{-1}$ and $K_{m} \sim 0.2 \mathrm{~g} \mathrm{~m}^{-2} \mathrm{~d}^{-1}$ [Matisoff and Neeson, 2005]) were used at Station 341 assuming that there have not been significant changes to the sediments. The system of differential equations (4) and (6) was solved to provide a SOD time series with 15 min time step.

\section{Results}

\subsection{Seasonal Patterns and Spatial Variability}

[16] External Forcing. Wind and heat flux recorded during the stratified summer period indicated similar trends for 2008 and 2009 with average wind speeds at $10 \mathrm{~m}, W_{10}$, between $\sim 4.3$ and $4.9 \mathrm{~m} \mathrm{~s}^{-1}$ (Figure 3) and average heat flux, $H_{p}$, between $\sim 250$ and $285 \mathrm{~W} \mathrm{~m}^{-2}$ (data not shown). The summer average wind is consistent with the wind distribution usually observed for Lake Erie [Boegman et al., 2008], and both years had seasonal patterns typical of summer conditions. A power spectral analysis of $W_{10}$ indicated a dominant daily breeze forcing for the early summer and a 10 day synoptic storm for the second part of the summer (after doy 200 in both years).

[17] Water Level. The water level with respect to sea

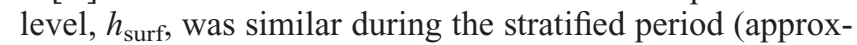
imately April to November) in terms of fluctuations and range, with $h_{\text {surf }}=174.24 \pm 0.14 \mathrm{~m}$ and $174.33 \pm 0.12 \mathrm{~m}$ in 2008 and 2009, respectively. The persistent $0.1 \mathrm{~m}$ difference in the water level between 2008 and 2009 was small relative to the $0.41 \mathrm{~m}$ difference in the water level measured over the stratified period between 1970-2000 and 2000-2010 $\left(h_{\text {surf } 1970-2000}=174.55 \pm 0.25 \mathrm{~m}\right.$ and $h_{\text {surf } 2000-}$ $2010=174.17 \pm 0.14 \mathrm{~m}$; Figure 4$)$. This would indicate that the measurement reported here occurred during a period of low water level condition relative to the 1980 s, for example, Mortimer [1987]. We also report, over the last century,
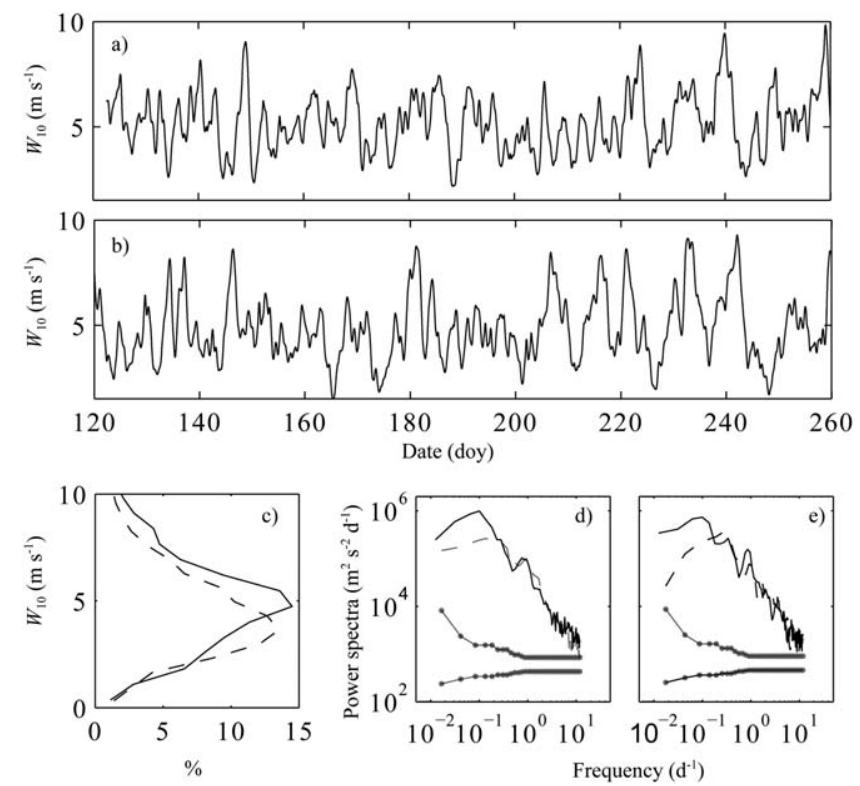

Figure 3. Wind speed at $10 \mathrm{~m}, W_{10}$, recorded at the Meteorological buoy (Station 341) in (a) 2008 and (b) 2009. (c) The distribution of the wind speed. ( $d$ and e) Power spectral density of the wind speed shown over two periods (before doy 200: dashed line; after doy 200: solid line). Lines with dot symbols in Figures $3 d$ and 3e represent the 95\% confidence level for the power spectral density (i.e., peaks exceeding this range would be considered significant).

$\mathrm{a} \sim 1.5 \mathrm{~m}$ maximum variability between the lowest (1935) and highest (1986) summertime water level in Lake Erie.

[18] Temperature. The lake started to stratify thermally $\left(N^{2}>10^{-4} \mathrm{~s}^{-2}\right)$ on doy 151 and 146 in 2008 and 2009, respectively. Heat and wind energy deepened the thermocline gradually, and depending on the station depth, the thermocline ultimately reached the bottom in the late summer (Figure 5). More precisely, the thermocline reached the bottom at our western station and then gradually propagated toward the offshore eastern stations because of the bottom slope (e.g., on doy 224, 236, 241, and 242 in 2008 and on doy 239, 241, 242, and 257 in 2009 at Stations 1227, 1228, 341, and 1231, respectively). An early summer deepening of the thermocline was observed

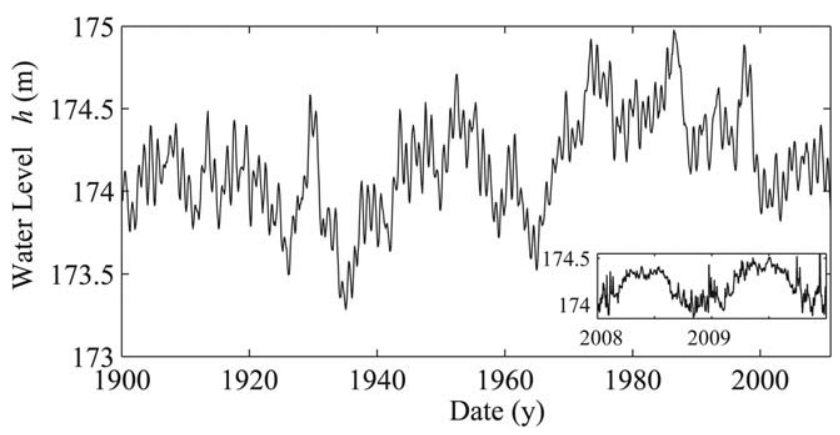

Figure 4. Monthly water level, $h$, recorded over one century at Buffalo. Inset presents the change in water level for 2008-2009 at higher frequency (6 min). 

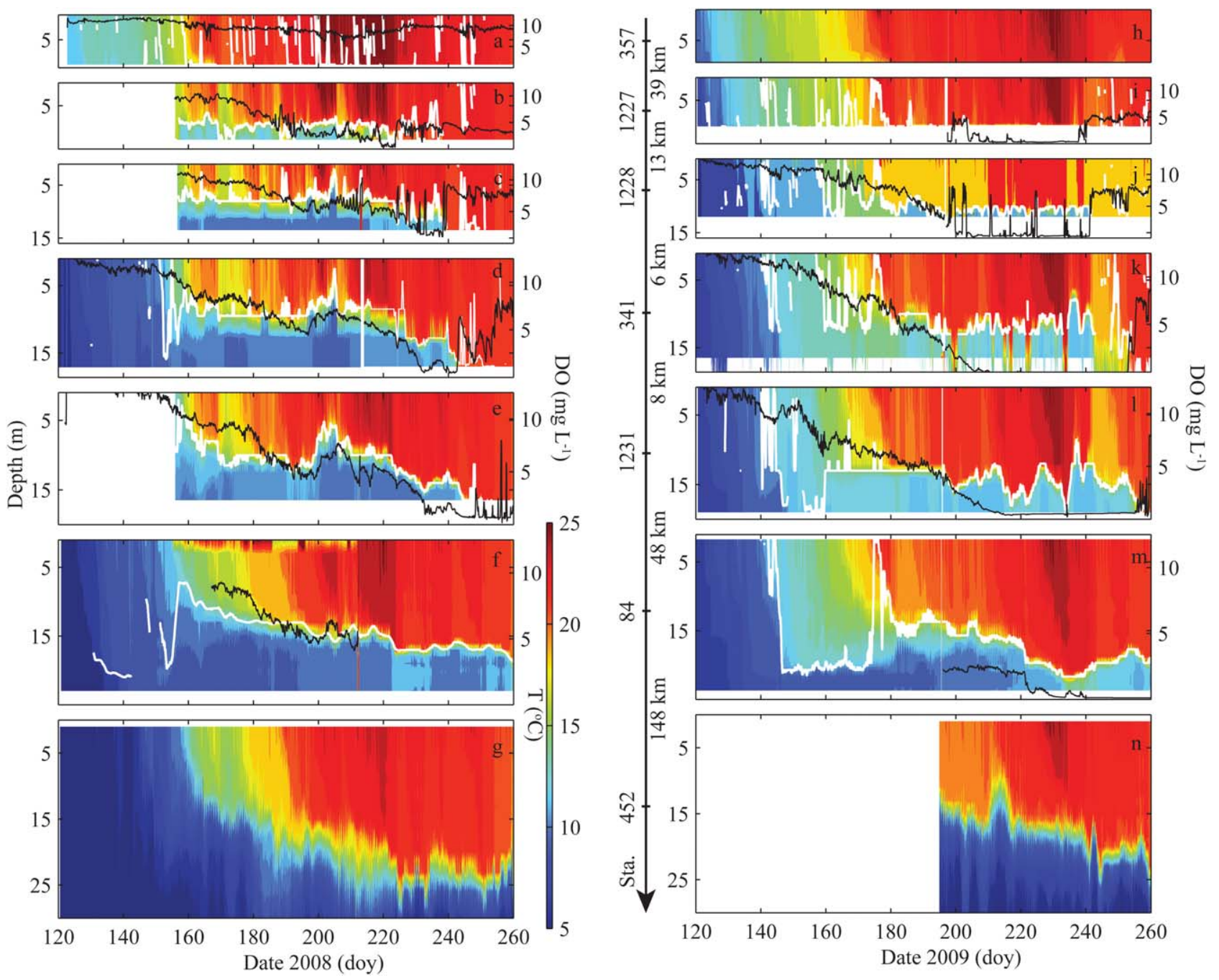

Figure 5. Time series of the depth distribution of water temperature, $T$, and dissolved oxygen, DO, presented at stations from west to east in 2008 ( $\mathrm{a}$ and $\mathrm{h}=$ Station 357 ; b and $\mathrm{i}=$ Station 1227 ; $\mathrm{c}$ and $\mathrm{j}=$ Station 1228; $\mathrm{d}$ and $\mathrm{k}=$ Station 341 ; e and $\mathrm{l}=$ Station $1231 ; \mathrm{f}$ and $\mathrm{m}=$ Station 84 ; and $\mathrm{g}$ and $\mathrm{n}=$ Station 452). The white line indicates the position of the thermocline $\left(N^{2}{ }_{\max }\right.$ with $\left.N^{2}{ }_{\max }>10^{-4} \mathrm{~s}^{-2}\right)$. The black line indicates DO in the hypolimnion. The entire $65 \mathrm{~m}$ depth at Station 452 (Figures $5 \mathrm{~g}$ and $5 \mathrm{n}$ ) is not shown to facilitate comparisons between panels. Station 357 is $28 \mathrm{~km}$ from the Detroit River.

until $\sim$ doy 160 when the thermocline stabilized for $\sim 30$ days at $12 \mathrm{~m}$ and $14 \mathrm{~m}$ in 2008 and 2009, respectively. The deep early summer thermocline was more pronounced in 2009. This period was followed by a large upwelling event at the HR stations (Stations 1227-1231) in 2008, which lasted for 9 days and moved the thermocline up to the surface at Station 1227. After this event, the thermocline deepened and then reached the bottom. The upwelling was not observed in 2009 , but a plateau was observed, indicating equilibrium between the external forcing and the vertical diffusivity of heat, and this was followed by a deepening of the thermocline.

[19] Hypolimnetic Water Temperature. Hypolimnetic water temperature is an important parameter as biochemical reactions, both in the water column and in the sediments, are enhanced by increased temperature [Charlton, 1980]. There were not, however, major differences between the hypolimnetic temperatures in 2008 and 2009, and the seasonal development was quite small (e.g., increasing from $5.6^{\circ} \mathrm{C}$ on doy 125 to $8.8^{\circ} \mathrm{C}$ on doy 140 and to $10.7^{\circ} \mathrm{C}$ on doy 230 in 2008 , and from $6.3^{\circ} \mathrm{C}$ on doy 125 to $8.9^{\circ} \mathrm{C}$ on doy 140 and to $10.9^{\circ} \mathrm{C}$ on doy 230 in 2009). The largest difference of $0.7^{\circ} \mathrm{C}$ on doy 125 disappeared on doy 140 .

[20] Organic Content of Suspended Particles. The concentration of Chl $a$ was used as a proxy to estimate the variability of the community respiration and production, respectively, in the hypolimnion. Results from in situ fluorometry indicated that the productivity could be neglected in the hypolimnetic DO budget as the upwelled natural fluorescence decayed exponentially to zero below the thermocline (Figure 6). The spatial variability of Chl $a$ among the four HR stations (i.e., Station 1227-1231) was not clear, and the data suggested a decrease in Chl $a$ from west to east in 2008 and an increase in 2009 (Figure 6). Although the difference was small, ranging from $\sim 2.5$ to $\sim 4 \mathrm{mg} \mathrm{L}^{-1}$, the same trend was evident in the organic component of the 

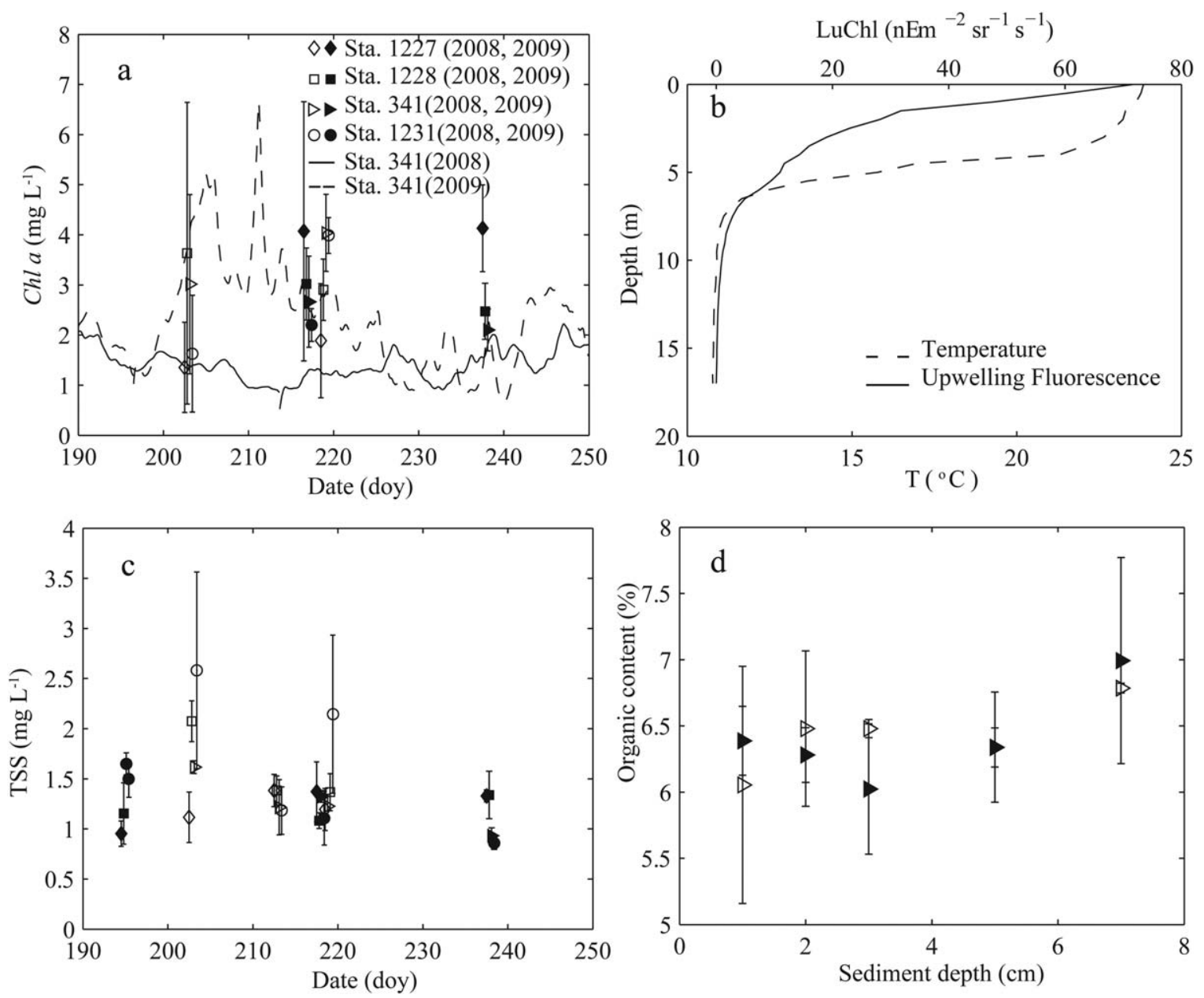

Figure 6. (a) Chlorophyll $a(\mathrm{Chl} a)$ at $z=12.5 \mathrm{~m}$; (b) example of fluorescence recorded on doy 203 at Station 341 using a Biospherical Instruments INF 300 fluorometer (San Diego, CA); (c) total suspended solids (TSS); and (d) percentage of organic content in the sediment in Station 341 measurements recorded during the water quality cruises at the HR stations. The $95 \%$ confidence interval is shown by vertical bar. A time series of Chl $a$ at Station 341 is shown in Figure 6a for 2008 (solid line) and 2009 (dashed line).

TSS water samples, which provide another proxy for community respiration (Figure 6). Results from the sediment traps in 2008 also indicated an eastward decrease in the rate of sedimentation of particles that had similar organic content $(\sim 18 \%$; Table 2$)$, which suggests that the productivity was relatively constant among our measuring stations, whereas the flow dynamics transporting the sediments were not (Figure 6).

[21] Flow. On a seasonal time scale, the flow in the hypolimnion was oriented mainly toward the south (Figure 7a), which is consistent with the circulation associated with
Ekman transport due to predominant westerly winds [Beletsky et al., 2012] and the counterclockwise gyre typically observed in that part of the lake [Saylor and Miller, 1987]. As a consequence, little exchange of fluid occurred between our HR stations (e.g., Stations 1227-1231) during the summer.

[22] An upwelling event in 2008 affected the circulation in the western end of the central basin for 9 days as indicated in the plot of the depth-averaged hypolimnetic current, $u_{\text {hypo }}$, recorded by the ADCP at Station 341 (Figure 7b). The interbasin exchange was significant as the

Table 2. Particulate Organic Matter Content in Sediment Traps Taken in the Western Part of the Central Basin of Lake Erie ${ }^{\mathrm{a}}$

\begin{tabular}{|c|c|c|c|c|c|c|}
\hline \multirow[b]{2}{*}{ Location } & \multicolumn{2}{|c|}{ Station 1228} & \multicolumn{2}{|c|}{ Station 341} & \multicolumn{2}{|c|}{ Station 1231} \\
\hline & $\begin{array}{l}\text { Sediment Flux } \\
(\mathrm{g} \mathrm{m}-2 \mathrm{~d}-1)\end{array}$ & $\begin{array}{c}\text { Organic } \\
\text { Content }(\%)\end{array}$ & $\begin{array}{l}\text { Sediment Flux } \\
(\mathrm{g} \mathrm{m}-2 \mathrm{~d}-1)\end{array}$ & $\begin{array}{c}\text { Organic } \\
\text { Content }(\%)\end{array}$ & $\begin{array}{l}\text { Sediment Flux } \\
(\mathrm{g} \mathrm{m}-2 \mathrm{~d}-1)\end{array}$ & $\begin{array}{c}\text { Organic } \\
\text { Content }(\%)\end{array}$ \\
\hline B-5 & 2.6 & 17 & 1 & 18.9 & 0.6 & 18.2 \\
\hline B-1 & & & 1.7 & 15.8 & 1.4 & 18.9 \\
\hline
\end{tabular}

${ }^{\mathrm{a} S e d i m e n t}$ traps were deployed on doy 120 and collected on doy 212 in 2008. 

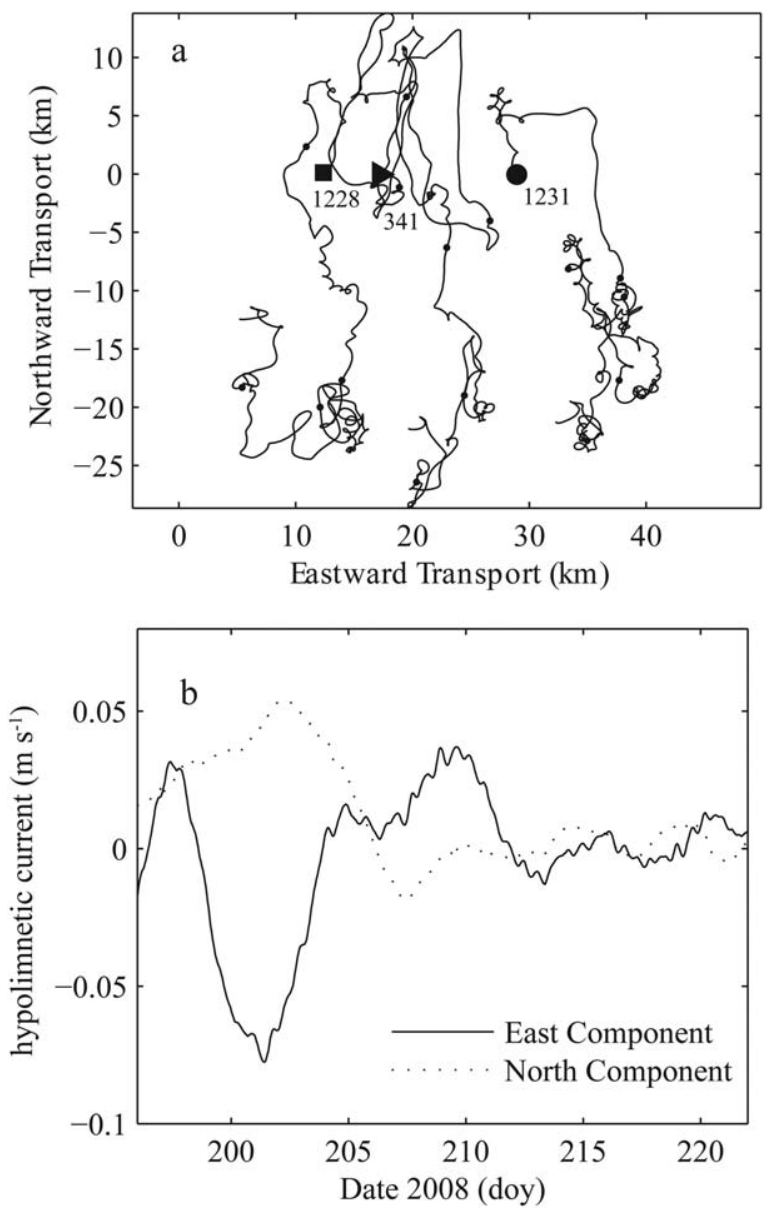

Figure 7. (a) Progressive vector plot diagram of the hypolimnetic current at B-4 at Stations 1228 (square), 341 (triangle), and 1231 (circle) between doy 160 and 195 in 2009. Comparable days are indicated on each progressive vector with dots (every 10 days). (b) Time series of the depth-averaged hypolimnetic current in 2008 during and after the upwelling. Note the asymmetry between the strong westward upwelling (doy 198-205) and the weaker southward and eastward oriented downwelling (doy 206-213). Data have been corrected by $7^{\circ}$ for magnetic declination.

upwelling was observed at Station 357 in the western basin, $38 \mathrm{~km}$ from the central basin (Figure 2). The westward directed flow between doy $T_{1}=198$ and $T_{2}=205$ corresponds to a transport of $\sim 21 \mathrm{~km}$ (i.e., distance $=$ $\left.1 /\left(T_{2}-T_{1}\right) \int_{T_{1}}^{T_{2}} u_{\text {hypo }} \mathrm{d} t\right)$ toward the western basin. This 21 $\mathrm{km}$ westward transport was balanced by a $9 \mathrm{~km}$ eastward transport between doy 206 and 213 (Figure 7b), which suggests that the return flow during the downwelling phase was not in the same direction, but, interestingly, followed the general lake circulation with a southeast trend in this part of the lake (Figure 7a).

[23] Oxygen Depletion. The DO at the onset of summer stratification was similar in 2008 and 2009; however, the rate of oxygen depletion, $\partial D O / \partial t$, varied over time from +0.28 to $-0.65 \mathrm{~g} \mathrm{~m}^{-3} \mathrm{~d}^{-1}$. The hypolimetic DO reached the hypoxic limit (i.e., $2 \mathrm{mg} \mathrm{L}^{-1}$ ) first at the shallowest western station and then extended offshore toward the east (e.g., at Stations 1227, 1228, 341, and 1231 on doy 213,
228, 229, and 232 in 2008, and at Sta tions 1228-1231 on doy 197, 199, and 203 in 2009; Figure 5). The same trend was observed when using the $5 \mathrm{mg} \mathrm{L}^{-1}$ lower water quality limit set by the International Joint Commission for the Great Lakes. From the beginning of the stratified period to the time that the thermocline reached the bottom, the mean oxygen depletion rate was slightly stronger in the west (e.g., Stations 1227, 1228, 341, and 1231 at $0.15,0.12$, 0.10 , and $0.10 \mathrm{mg} \mathrm{L}^{-1} \mathrm{~d}^{-1}$ in 2008 and at $0.13,0.12,0.11$, and $0.10 \mathrm{mg} \mathrm{L}^{-1} \mathrm{~d}^{-1}$ in 2009 , respectively).

[24] The rate of oxygen depletion was compared to the hypolimnion thickness $(H)$ with a robust-fit method using values that were averaged over 2 day windows at times when the thermocline was stationary. Results indicated a good fit with $H^{-1}\left(r^{2}=0.96\right.$; Figure 8$)$ as predicted by equation (3), and, as a consequence, equation (3) provided an estimate for $\mathrm{SOD}=0.46 \pm 0.08 \mathrm{~g} \mathrm{~m}^{-2} \mathrm{~d}^{-1}$ and $\mathrm{HOD}=0.07 \pm 0.04 \mathrm{~g} \mathrm{~m}^{-3} \mathrm{~d}^{-1}$. This simple model indicates an association between hypolimnion thickness and oxygen depletion rate. The spatial variability in $\partial D O / \partial t$ over the four HR stations was within the range of uncertainty for one station (Station 341) and was due to different summer-averaged hypolimnion thicknesses at each site. Consequently, the data from all stations were pooled.

\subsection{High-Frequency Patterns}

[25] Water Level. The change in water level at daily time scales was small and due to oscillations from the $15 \mathrm{~h}$ barotropic surface seiche [Rao et al., 2008]. The depth recorder at Sta tion 341 indicated a maximum oscillation of $0.3 \mathrm{~m}$ related to the surface seiche activity. Although this oscillation did not affect the DO budget at the thermocline, the associated barotropic current was responsible for an enhanced oxygen depletion rate at the sediment-water interface (see below).

[26] Thermocline. A $17 \mathrm{~h}$ Poincaré wave period was responsible for $\leq 2 \mathrm{~m}$ variation of the thermocline depth (Figure 5). Bouffard et al. [2012] found that Poincaré wave induced mixing and changed the energy budget over the water column with higher dissipation levels than are

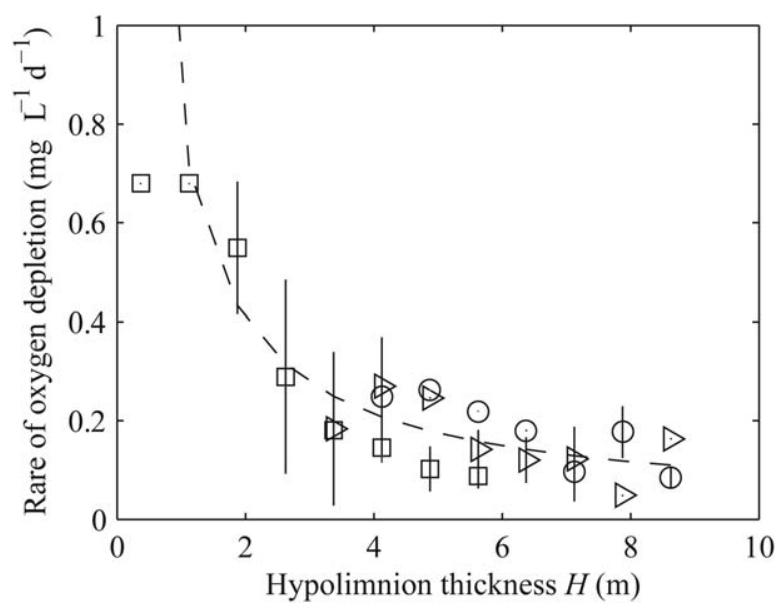

Figure 8. Rate of oxygen depletion as a function of the hypolimnion thickness for Stations 1228 (square), 341 (triangle), and 1231 (circle) in 2008 and 2009. Data have been bin averaged over $\Delta H=0.5 \mathrm{~m}$ at each station. 
usually expected in the thermocline region [Wüest and Lorke, 2003]. The geometric-averaged vertical diffusivity (equation (1)) found in the thermocline region was $K_{z} \sim 3$ $\times 10^{-6} \mathrm{~m}^{2} \mathrm{~s}^{-1}$ (Figure 2), and the average flux through the thermocline (i.e., equation (2)) was $0.14 \pm 0.16 \mathrm{~g} \mathrm{~m}^{-2} \mathrm{~d}^{-1}$ (Figure 9). At the thermocline interface, Poincaré wave activity had a strong influence on the hypolimnetic DO signal. It was estimated from equation (2) that $12 \mathrm{~g} \mathrm{~m}^{-2}$ (or 1.5 $\mathrm{mg} \mathrm{L}^{-1}$ assuming a mean $H=8 \mathrm{~m}$ ) of DO was transferred from the epilimnion to the hypolimnion through this baroclinic activity over the summer (June to August).

[27] Sediment Oxygen Demand. Both surface seiches and Poincaré waves were responsible for the currents flowing above the sediments. Rotary power spectral analysis of the hypolimnetic current conducted in the spring (Figure 10a) and the summer (Figure 10b) indicated that surface seiches are dominant during the spring (e.g., peak in both clockwise and counterclockwise component at $\sim 15 \mathrm{~h}$ ) and Poincaré waves are dominant during the summer (e.g., clockwise peak only). Using a modal decomposition, Valipour [2012] found that baroclinic motion accounted for $70 \%$ of the variability in the bottom shear stress. We, therefore, focus mainly on baroclinic motion (e.g., Poincaré waves). This hydrodynamic forcing affected the DO flux as stronger currents compress the diffusive boundary layer and, therefore, facilitate DO transfer through the sedimentwater interface. An $\sim 8 \mathrm{~h}$ oscillation in the forcing ( $u^{*}$; Figures 9d and 10d) was observed, resulting in a similar oscillation in the SOD. The $\sim 8 \mathrm{~h}$ oscillation corresponds to half of the forcing period as shear is sensitive to the absolute value of the current. Strong Poincaré wave activity was associated with elevated SOD, and a mean SOD of $0.41 \pm 0.36 \mathrm{~g} \mathrm{~m}^{-2} \mathrm{~d}^{-1}$ was observed over the measurement period (Figure 9). There is no reverse current associated with the rotary nature of a progressive Poincaré wave, as opposed to the oscillating current in a wind-induced free surface standing wave, and thus, it is reasonable to consider the turbulence as fully developed during all phases of the Poincaré wave, i.e., equations (4) and (5) may be correctly applied to this type of flow. Similar results arise from the Batchelor length scale $\left(L_{B}\right)$, which follows the same trend as $\delta_{\mathrm{DO}}$ DBL . We note, however, that $L_{B}$ systematically overestimated the diffusive length scale by $42 \%$, which is why we prefer $\delta_{\mathrm{DO}}$ (equation (5)); this has been validated by Hondzo [1998] at the laboratory scale.

[28] Hypolimnetic Oxygen Demand. We were unable to investigate the high-frequency (i.e., seconds to hours) variability of the biological activity that consumed DO in the hypolimnion. This is likely because biogeochemical rate equations respond at longer periods (greater than diurnal)
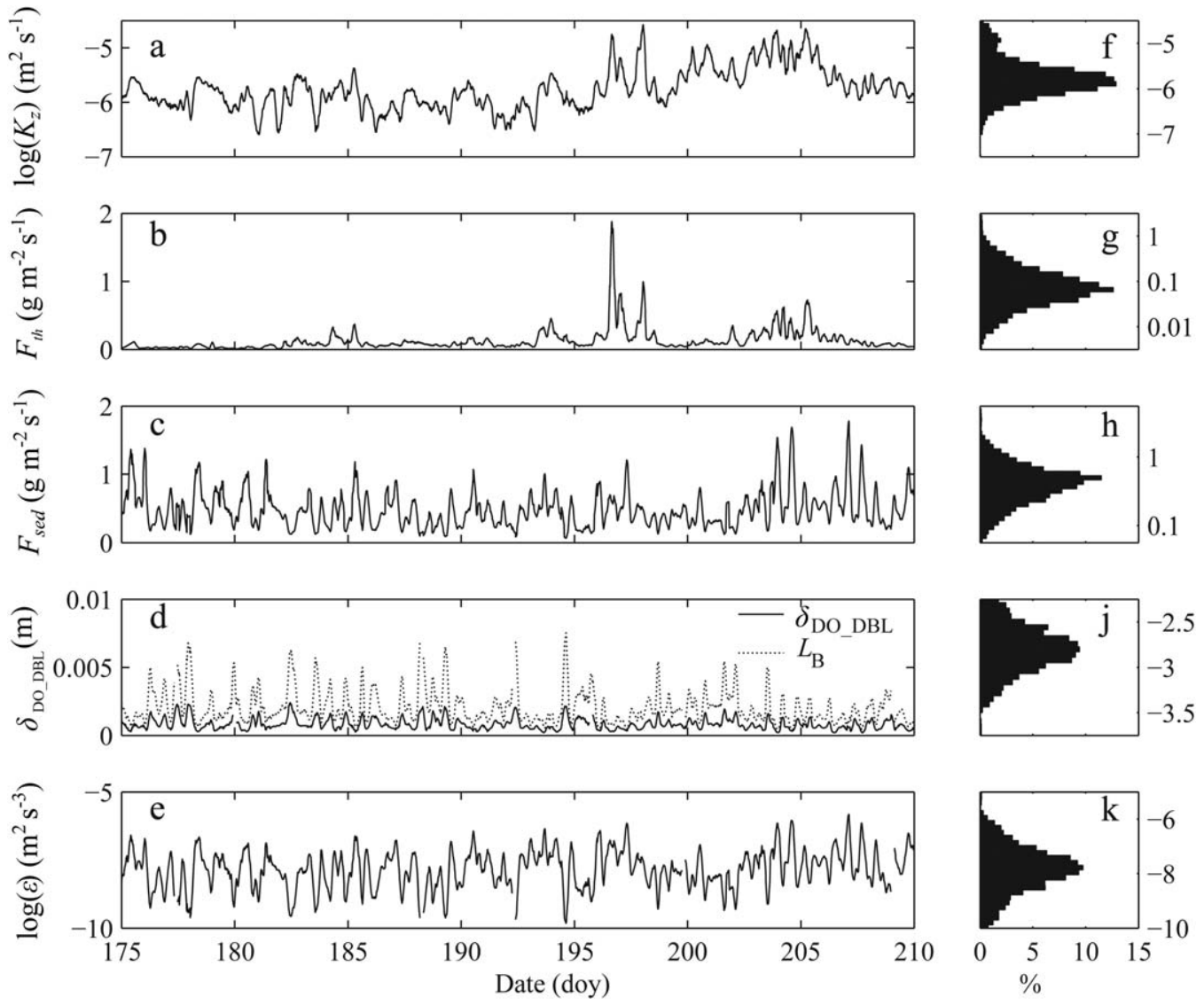

Figure 9. Nature of the flux and related measurements from Station 341. (a) Vertical diffusivity, $K_{z}$, estimated in the thermocline region, (b) flux of oxygen transported through the thermocline, $F_{\text {th }}$, and (c) through the sediment-water interface, $F_{\text {sed }}$, (d) diffusive boundary layer thickness, $\delta_{\mathrm{DO}} \mathrm{DBL}_{\text {, }}$ (equation (3)) compared to the Batchelor length scale $\left(L_{B}\right)$, and (e) the rate of dissipation of turbulent kinetic energy, $\varepsilon$, at B-1 calculated from the HR ADCP. ( $\mathrm{f}-\mathrm{k})$ The logarithmic distribution of the parameters shown in Figures 9a-9e. 

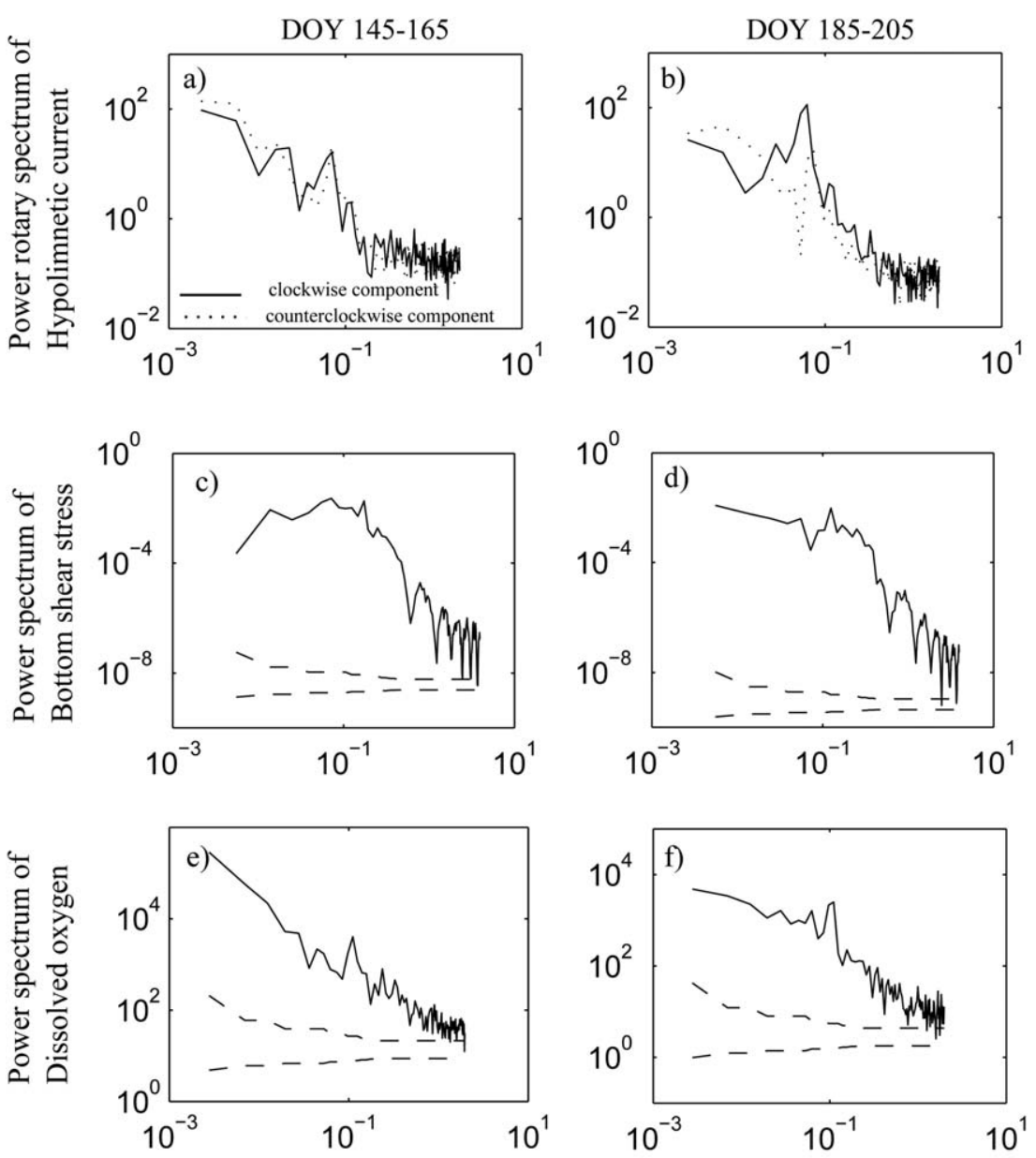

Frequency $\left(\mathrm{d}^{-1}\right)$

Figure 10. Spectra analysis of the current (a and b), the bottom shear stress ( $c$ and d), and dissolved oxygen (e and f) during two 20-day period (doy 145-165: Figures 10a, 10c, and 10e; doy 185-205: Figures $10 \mathrm{~b}, 10 \mathrm{~d}$, and 10f). The rotary spectra indicate surface seiche activity in Figure 10a with both clockwise and counterclockwise components. The rotary spectra in Figure 10b indicate Poincaré wave activity with only clockwise components. Dashed lines (Figures 10c-10f) represent the limits of the $95 \%$ confidence level (i.e., peaks exceeding this range would be considered significant).

to factors such as ambient light and temperature, whereas high-frequency hydrodynamics processes, such as shear instabilities, have $\sim 100$-s periods [Bouffard et al., 2012]. The only short-term biogeochemical variability observed was the diurnal fluctuation in Chl $a$ related to light condition at $z=12.5 \mathrm{~m}$ (i.e., $\pm 0.15 \mu \mathrm{g} \mathrm{L}^{-1}$ centered around a typical Chl $a$ value of $2 \mu \mathrm{g} \mathrm{L}^{-1}$ ); however, the upwelled fluorescence data (Figure 6b) suggest that photosynthetic activity was negligible below the thermocline and that the small short-term variability in the Chl $a$ proxy can be neglected. HOD was, therefore, parameterized using a constant value for the summer of $0.07 \mathrm{~g} \mathrm{~m}^{-3} \mathrm{~d}^{-1}$ as found in equation (2). Although this HOD estimate is an oversimplification, the value agrees well with values reported elsewhere (e.g., 0.067-0.12 $\mathrm{g} \mathrm{m}^{-3} \mathrm{~d}^{-1}$, Charlton and Milne [2004]; 0.07-0.12 $\mathrm{g} \mathrm{m}^{-3} \mathrm{~d}^{-1}$, Rosa and Burns [1987]; 0.065-0.10 $\mathrm{g} \mathrm{m}^{-3} \mathrm{~d}^{-1}$, Charlton [1980]). If we exclude the early Chl $a$ peak from our study, which was prior to the period of interest, both Chl $a$ and the organic content of TSS in the hypolimnion remained in the same range over the summer (Figure 6). Our estimate is at the lower end of the range reported historically, but the steady reduction in phosphorus loading, which is linked to HOD, may explain this difference. We, therefore, focus on the small-scale physical factors affecting the DO variability. Future improvement of the following model will come from a better parameterization of the variability in HOD.

[29] Dissolved Oxygen. There was an $8 \mathrm{~h}$ peak in the DO power spectra (Figures 10e and 10f), which indicated that the DO was affected by the Poincare wave activity or the surface seiche activity in the spring. This result was consistent with the oscillation at the sediment-water interface and thermocline fluxes reported above. A coherence analysis [e.g., Loewen et al., 2007] between wind speed fluctuation as the input and DO as the output indicated that the variation in the former explained $\sim 16 \%$ of the variation in DO. A multiple coherence analysis using friction velocity $\left(u^{*}\right)$, the oscillation in the hypolimnion thickness $(H)$, and 
the thermocline flux $\left(F_{\text {th }}\right)$ as inputs indicated that variations in these input signals accounted for $\sim 68 \%$ of the variation in the DO.

\section{Discussion}

[30] The mechanisms leading to changes in hypolimnetic DO are complex and involve a number of hydrodynamic processes. To evaluate the relevance of these processes to oxygen depletion, the relative contribution of the different sources and sinks of DO were assessed by comparing the data to a 2-D model of the hypolimnetic oxygen budget. The model includes, over a 15 min time step, the vertical flux of oxygen through the thermocline $\left(F_{\text {th }}\right)$ and the sediment $\left(F_{\text {sed }}\right)$, the HOD and the advection $(U$ and $V)$ calculated with the upward-looking ADCP from Station 341, and the DO data from the surrounding stations,

$$
\frac{\partial \mathrm{DO}}{\partial t}=\frac{F_{\mathrm{th}}}{H}+U \frac{\Delta \mathrm{DO}}{\Delta x}+V \frac{\Delta \mathrm{DO}}{\Delta y}-\frac{F_{\mathrm{sed}}}{H}-\mathrm{HOD} .
$$

[31] The model is an extension of Edwards et al. [2005] and Rao et al. [2008] that better captures high-frequency changes in the DO budget by including advection, a better vertical diffusivity model validated against microstructure measurements (equation (1)) and a predictive SOD algorithm (equations (5) and (6)). The model represents the oxygen depletion and its variability quite well with a normalized root-mean-square error between the field data and the model of $0.44 \mathrm{mg} \mathrm{L}^{-1}$ (i.e., $11 \%$ ) in 2008 and $0.65 \mathrm{mg} \mathrm{L}^{-1}$ (i.e., $16 \%$ ) in 2009 (Figure 11a). Moreover, the increase of oxygen in the hypolimnion between doy 196 and 205 at Station 341 in 2008 was also reproduced well by the model.

\subsection{Flux Through the Thermocline}

[32] Our results suggest that vertical turbulent diffusivity is responsible for the injection of a considerable flux of oxygen into the hypolimnion relative to molecular transfer through the thermocline (i.e., $12 \mathrm{~g} \mathrm{~m}^{-2}$ versus $1.05 \mathrm{~g} \mathrm{~m}^{-2}$ over the 90 day stratified period). This corresponds to an oxygen source equivalent to $\sim 18 \%$ of the total oxygen depleted in the hypolimnion $(\sim 20 \%$ in 2008 and $\sim 16.5 \%$ in 2009). Bouffard et al. [2012] have shown that the Poincaré wave activity was a significant source of turbulence in the thermocline region of Lake Erie and was acting as a trigger for short internal waves locally increasing mixing. This flux may delay the occurrence of hypoxia by $\sim 12$ days in 2008 if the flux through the thermocline is neglected in the DO budget. Some studies argued the importance of the initial DO concentration (or temperature) at the onset of the stratification to hypoxia [Molot et al., 1992]. For example, the flux of DO through the thermocline from June to August corresponded to an increase of the nonstratified spring temperature from $5^{\circ} \mathrm{C}$ to $9^{\circ} \mathrm{C}$ (assuming DO saturation in the spring of $\mathrm{DO}_{\text {sat }}\left(9^{\circ} \mathrm{C}\right) \sim$ $11.5 \mathrm{mg} \mathrm{L}^{-1}$ and $\mathrm{DO}_{\text {sat }}\left(5^{\circ} \mathrm{C}\right) \sim 12.7 \mathrm{mg} \mathrm{L}^{-1}$ from Weiss [1970]). This range in temperature $\left(\sim 5^{\circ} \mathrm{C}\right.$ to $\left.9^{\circ} \mathrm{C}\right)$ corresponds to the extremes of spring temperature in the central basin of Lake Erie [Schertzer, 1987]. It is relevant to compare this 12 day delay to the 2.5 day per decade estimate for the increase of the stratified season in the more northerly Lake Superior [Austin and Colman, 2008]. The influence of the vertical flux through the thermocline seems to be of the same order of importance compared to the effect of temperature on the onset of the stratification and the duration of the stratified season.

\subsection{Sediment Oxygen Demand}

[33] The variation in SOD could be explained by the barotropic and baroclinic activities; however, the total contribution of the Poincare wave to the oxygen in the hypolimnion was more complex than the contribution from surface seiches. Although both surface seiche and Poincaré wave activities induced shear at the lake bed and increased the SOD, Poincaré waves, as a baroclinic motion, had a
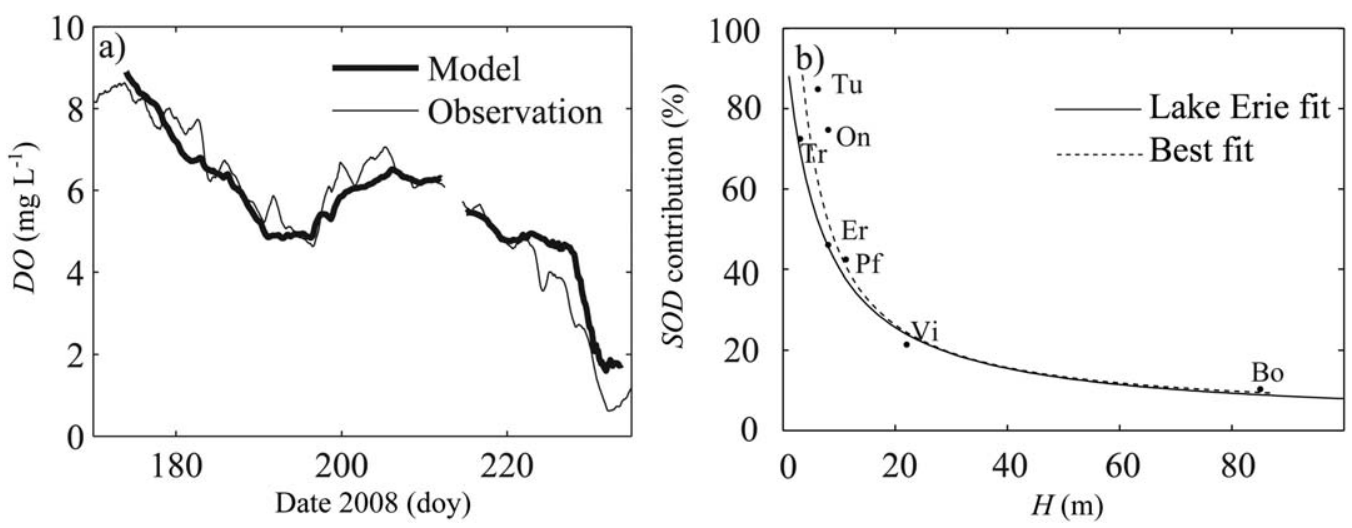

Figure 11. (a) Comparison of the dissolved oxygen concentration, DO, in the hypolimnion observed at Station 341 in 2008 and as modeled from equation (7). (b) Relative contribution of hypolimnetic sediment oxygen demand, SOD, to oxygen depletion as a function of the lake depth reported for a variety of lakes. Bo: Lake Bourget, France [Viollier et al., 2007]; Vi: San Vicente Reservoir, USA [Beutel et al., 2007]; Pf: Lake Pfaffikersee, Switzerland [Matzinger et al., 2010]; Er: Lake Erie, (present study); On: Lake Onondaga, USA [Matthews and Effler, 2006]; Tu: Lake Tuerlersee, Switzerland; and Es: Lake Truite, Canada [Cornett and Riggler, 1987]. Line shows the relative contribution of SOD / $H$ to oxygen depletion as a function of the hypolimnion thickness, $H$, (extended to $100 \mathrm{~m}$ ) using $\mathrm{SOD}=0.46 \mathrm{~g} \mathrm{~m}^{-2}$ $\mathrm{d}^{-1}$ and $\mathrm{HOD}=0.07 \mathrm{~g} \mathrm{~m}^{-3} \mathrm{~d}^{-1}$. 
strong shear signature through the thermocline and therefore enhanced the oxygen flux (section 4.1). The increase in DO through the thermocline was, however, balanced by an increase of the water-sediment flux and, in any case, Poincaré waves have a negative role for the hypolimnetic DO balance as described above (Figure 9).

[34] The properties of the sediment were held constant under the assumption in the model (equation (6)) that the biogeochemical time scale for change in the sediment exceeds the seasonal time scale. This assumption is reasonable given that the analysis of the sediment cores (Station 341) indicated that the organic content remained constant $\sim 6.3 \% \pm 0.2 \%$ within the first $6 \mathrm{~cm}$ depth and then increased to $6.8 \% \pm 0.1 \%$ deeper in the sediments (Figure 6d). This is supported by results from Matzinger et al. [2010], which demonstrated that there was a lag of at least 10 years in the contribution of sediments to the SOD in the two lakes they examined. It is important to note that our model was relatively insensitive to the lower and higher sediment properties $\left(R_{m}\right)$ reported by Matisoff and Neeson [2005]. A 50\% change in the model of the sediment properties modifies SOD by $17 \%$, whereas a $50 \%$ change in the shear stress modifies SOD by $42 \%$ ( $8 \%$ and $22 \%$ for the DO budget, respectively). We suggest that SOD is controlled more by shear stress than by microbial oxygen uptake rate. This result is consistent with the recent large eddy simulation from Scalo et al. [2012] showing that the concentration of DO at the sediment-water interface is limited by the turbulence in the water layer; the microbial activity in the sediment contributes to the DO distribution in the sediments (e.g., shape of the exponential decay), but is less important to the flux of oxygen through the sediment-water interface. Bottom boundary layer dynamics should be considered when investigating the HOD at seasonal scales.

[35] Under these conditions, it is reasonable to investigate the temporal variability in SOD as a function of the hydrodynamic forcing. We begin by noting that the magnitude of SOD in this study $\left(0.41 \pm 0.07 \mathrm{~g} \mathrm{~m}^{-2} \mathrm{~d}^{-1}\right)$ is consistent with previous reports from the central basin of Lake Erie including $\sim 0.2$ to $0.3 \mathrm{~g} \mathrm{~m}^{-2} \mathrm{~d}^{-1}$ in a dome-shaped chamber [Snodgrass, 1987; Snodgrass and Fay, 1987]; $\sim 0.8$ to $0.9 \mathrm{~g} \mathrm{~m}^{-2} \mathrm{~d}^{-1}$ in a tetrahedron-shaped chamber [Snodgrass, 1987; Snodgrass and Fay, 1987]; and $0.28 \mathrm{~g}$ $\mathrm{m}^{-2} \mathrm{~d}^{-1}$ by gently mixing the fluid while using oxygen microelectrode profiling [Matisoff and Neeson, 2005]. Numerical models have determined that the chamber geometry strongly affected the hydrodynamic conditions resulting in weakly turbulent flow in a dome-shaped chamber and actively turbulent flow in a tetrahedron-shaped chamber [Lee et al., 2000]. It is not unreasonable to suggest that the range in SOD measured in this study occurred under a range of turbulent conditions, including those generated in the aforementioned benthic chambers. Our SOD estimate is also similar to other mesotrophic lakes (e.g., 0.34-0.43 g $\mathrm{m}^{-2} \mathrm{~d}^{-1}$ in Tuerlersee and Pfaffikersee; Matzinger et al. [2010]).

[36] We used a single box model for the hypolimnion in equation (7). This hypothesis was supported by the absence of DO gradient observed in the hypolimnion, which is a result of the faster time scale for mixing of the DO scalar in the bottom boundary layer compared to the SOD time scale in the diffusive boundary layer [Loewen et al., 2007]. We estimate the mixing time scale in the bottom boundary layer as $T=H^{2} / K \sim 8 \mathrm{~min}$, with $K=0.41 H u^{*}, H=1 \mathrm{~m}$ and $u^{*} \sim 2 \times 10^{-3} \mathrm{~m} \mathrm{~s}^{-1}$ (mean value calculated over the summer at $H=1 \mathrm{~m}$ ). This mixing time scale is always much larger than the time it takes for SOD to setup a DO gradient near the bottom (outside the diffusive boundary layer), i.e., to reduce by an arbitrary chosen $\Delta \mathrm{DO}=0.1 \mathrm{mg}$ $\mathrm{L}^{-1}$ within a $\Delta z=1 \mathrm{~m}$ layer above the sediments: $T_{\mathrm{SOD}}=$ $(\Delta z \Delta \mathrm{DO}) / \mathrm{SOD} \sim 5 \mathrm{~h}$. This simple calculation shows that any weak DO stratification near the bottom cannot be sustained, the only gradient being in the diffusive boundary layer.

[37] The oxygen budget presented in equation (7) provides information on the relative importance of the two sink terms, SOD and HOD. In terms of partitioning the oxygen depletion over the summer, SOD accounted for $51 \%$ and $53 \%$ in 2008 and 2009, respectively (calculated as $(\mathrm{SOD} / H) /(\mathrm{SOD} / H+\mathrm{HOD}))$, whereas HOD was responsible for the remaining $49 \%$ and $47 \%$, respectively. This contribution of SOD is comparable but slightly larger than the results from a nine box basin-width model applied to Lake Erie, which attributed $48 \%$ and $47 \%$ of the oxygen depletion in 1972 and 1979, respectively, to SOD [ Lam et al., 1987]. Given that the SOD estimates have not changed since the mid-1980s [Snodgrass, 1987; Snodgrass and Fay, 1987], changes in the phosphorus loading may have had a greater effect on the HOD than the SOD, perhaps due to the lag described above. This is different from what Smith and Matisoff [2008] reported from a mooring closer to the center of the central basin where they used three methods to determine that the mean SOD ranged from 0.1 to $0.2 \mathrm{mg} \mathrm{L}^{-1} \mathrm{~d}^{-1}$. They suggested that this low value could be due to the reduction in phosphorus loading; however, such reductions should have also affected the HOD and the rate of oxygen depletion. Given that the rate of oxygen depletion has declined from 1972 to 1986 and then increased afterward [Burns et al., 2005; Rucinski et al., 2010], the direct relationship between phosphorus loading and DO depletion is questionable. In addition, the low SOD range found by Smith and Matisoff [2008] could also be associated with weak basin-scale internal wave activity at their mooring, resulting in reduced bed shear stress and ultimately low SOD (i.e., a reduction of the bed shear stress by a factor of 2 to 3 associated to the spatial variability in the Poincaré wave or surface seiche activity would affect SOD as it is proportional to $u^{*}$; equations (4) and (5)). Alternatively, the low SOD value reported by Smith and Matisoff [2008] could be partially related to a lower organic content in the sediments at their site $(3 \%)$ than was observed in this study $(6 \%$; Figure $6 \mathrm{~d})$. It is relevant to note that their biogeochemical reaction network simulator predicted a SOD $\sim 0.32 \mathrm{~g} \mathrm{~m}^{-2} \mathrm{~d}^{-1}$ [Smith and Matisoff, 2008, Figure 7] based on 6\% organic content $\left(0.25 \mathrm{~g} \mathrm{~m}^{-2} \mathrm{~d}^{-1}\right.$ using $3 \%$ organic, e.g., $28 \%$ increase), which is $\sim 30 \%$ lower than our estimate. According to our sensitivity analysis, a 50\% change in the sediment properties would lead to an increase of $17 \%$ (or $28 \%$ according to the biogeochemical reaction network model used in Smith and Matisoff [2008]) in the SOD. A numerical or analytical map of the basin-scale internal wave activity driving $u^{*}$ would be of value as would information on the spatial variation in the organic concentration in the bottom sediments. 


\subsection{Advection}

[38] Our results (Figure 7a) agree well with numerical [León et al., 2005] and field observations [Saylor and Miller, 1987], which have found a large counterclockwise gyre at the western portion of the central basin of Lake Erie that pushes water to the southern shore at the western end. Given this southward transport, it was somewhat surprising that advection needed to be included in the model (equation (7)). This was certainly the case in 2008 when an upwelling event (Figure $7 \mathrm{~b}$ ) associated with strong water movement was observed (determined from the ADCP from Station 341 and the DO data logger from the four surrounding stations). In this case, advection explained $\sim 50 \%$ of the DO source in 2008 for this period (doy 195-205). Otherwise, advection could have been neglected due to the small mean flow and DO gradient, as was the case at other times in 2008 and in 2009 ( $<5 \%$ of the rate of oxygen depletion time record). The elliptical current associated with the Poincaré wave oscillation probably reduced the importance of the advection. If we assume that the Poincare wave current ranges from 0.05 to $0.2 \mathrm{~m} \mathrm{~s}^{-1}$, then this process [Bouffard et al., 2012] would advect DO within an inertial circle of radius, $R_{\mathrm{PW}}=u T_{\mathrm{PW}} / 2 \pi$, where $T_{\mathrm{PW}}$ is the period of the Poincaré wave, ranging from 0.5 to $2 \mathrm{~km}$. Advection has a significant role only during upwelling or downwelling events, with the upwelling providing oxygenated deep water to the western end of the central basin with a westnorthwest current (Figure 7b). The upwelled water from the central basin is then mixed with nutrient-rich western basin water [Ackerman et al., 2001] before being carried toward the Sandusky Basin by the characteristic southward circulation. The returning southerly current did not supply nutrients to our stations; rather it likely increased the nutrient concentration in the Sandusky Basin. That part of the lake is known to experience the strongest and earliest hypoxia conditions in most years [Conroy et al., 2010]. The loading from the Sandusky River and the lake circulation may help to explain this observation. Our sediment traps confirmed this hypothesis as we found a slight increase in the rate of sedimentation from east to west (Stations 12311228; Table 2). It appears that during these upwelling events that the western basin act as a reactor providing organic content and oxygen depleted water to the south shore of the central basin. Unfortunately, the spatial orientation of our stations was not optimized to examine this phenomenon in greater detail. It is relevant to note that this largescale circulation has also been found in a 3-D numerical model [León et al., 2005] of summer conditions and may be an important local feature for hypoxia.

\subsection{Hypolimnion Thickness}

[39] Hypolimnion thickness, $H$, was found to be the most important parameter related to oxygen depletion as is shown in Figure $11 \mathrm{~b}$. The time-averaged SOD estimated as a function of the sediment properties and the hydrodynamic conditions (equation (4)) is similar to the value found using equation (3) at a seasonal scale (e.g., 0.41 and $0.46 \mathrm{~g} \mathrm{~m}^{-2}$ $\mathrm{d}^{-1}$, respectively). Moreover, the thickness of the hypolimnion appears to be of first-order importance in explaining the large difference in oxygen depletion between 2008 and 2009. The variability between 2008 and 2009 is explained by the difference in the deepening of the thermocline. The relationship between the hypolimnion thickness and the oxygen depletion is evident both on an hourly and a seasonal oxygen depletion rate budget through the term $\mathrm{SOD} / H$. This is not a new result [Charlton, 1980], but we are able to present a detailed budget that quantifies the importance of the barotropic and baroclinic activities with respect to the strong interannual variability observed in Lake Erie. The multiple coherence analysis from section 3.2 has shown that $84 \%$ of the variance of DO was explained by barotropic and baroclinic activities. From the modal decomposition presented in Valipour [2012], we estimate that $70 \%$ of the oscillations in the currents were due to the baroclinic motions, and we infer from these data that there was a $58 \%$ contribution from baroclinic motion, a $26 \%$ contribution from barotropic motion, and a $16 \%$ direct contribution from the wind on the oscillation in DO.

[40] Although most lakes have a relatively consistent multiyear trend in DO depletion rate, the oxygen depletion rate in Lake Erie appears rather erratic [Matisoff and Neeson, 2005]. We assert that the shallow water of the central basin is responsible for this variability and that predicting the hypoxia at the end of the summer would have been difficult without an accurate prediction of the hypolimnion thickness. This was certainly the case for the early summer deep stratification in 2009 and the large upwelling in 2008 (Figure 5). Both events illustrate the ability of hypolimnion thickness to overcome yearly trends and thus also mask potential changes in water quality. The hypolimnetic oxygen depletion rate would depend primarily on the HOD during periods when the hypolimnion is thick, whereas $\mathrm{SOD} / H$ would be more important during periods when the hypolimnion is thin (Figure 11b). Moreover, equation (3) indicates that a deeper hypolimnion would be more responsive to a change in the nutrient loading through the predominance of the HOD term. Conversely, a shallow hypolimnion would be less responsive to nutrient loading as SOD integrates the long-term history of sediment properties. In the case of the central basin, it would take a minimum of 10 years to significantly modify the biogeochemical properties in the sediment given a sedimentation rate of $1.7 \mathrm{~mm} \mathrm{yr}^{-1}$ (e.g., Kemp et al. [1977] and assuming an aerobic sediment layer of approximately 1-2 $\mathrm{cm}$; Matisoff and Neeson [2005]).

[41] Evidence of improvements to water quality could also be affected by the significant decrease in the water level of Lake Erie that have occurred over the past 40 years, i.e., a $0.4 \mathrm{~m}$ of difference accounted for $4 \%$ of the oxygen depletion in 2008 and 6\% in 2009 using equation (3). Moreover, baroclinic motions in the shallow central basin of Lake Erie are more efficient at increasing the oxygen flux across the sediment-water interface than the flux across the thermocline, which would exacerbate the hypoxia. The interrelationships between wind, stratification, mixing, and hypoxia are somewhat paradoxical. In a weakly stratified system (e.g., the western basin of Lake Erie; Loewen et al. [2007]), winds $>6 \mathrm{~m} \mathrm{~s}^{-1}$ will increase turbulent mixing of DO and reduce the rate of oxygen depletion. However, strong wind events will deepen (not mix) seasonal stratification (e.g., central and Sandusky basins of Lake Erie), thinning the hypolimnion and correspondingly increasing the rate of oxygen depletion [Conroy et al., 2010]. We suggest here that not only strong wind events but also the 
Table 3. Seasonal Time-Scale Comparison of HOD and SOD in Different Lakes

\begin{tabular}{|c|c|c|c|c|}
\hline Lake & $\begin{array}{l}\text { Hypolimnetic Oxygen } \\
\text { Demand }\left(\mathrm{g} \mathrm{m}^{-3} \mathrm{~d}^{-1}\right)\end{array}$ & $\begin{array}{l}\text { Sediment Oxygen } \\
\text { Demand }\left(\mathrm{g} \mathrm{m}^{-2} \mathrm{~d}^{-1}\right)\end{array}$ & $\begin{array}{c}\text { Hypolimnion } \\
\text { Thickness, } H(\mathrm{~m})\end{array}$ & References \\
\hline Erie & 0.07 & 0.46 & 8 & Present study \\
\hline Bourget & 0.048 & 0.48 & 85 & Viollier et al. [2007] \\
\hline San Vicente & 0.082 & 0.43 & 22 & Beutel et al. [2007] \\
\hline Pfaffikersee & 0.06 & 0.44 & 12 & Matzinger et al. [2010] \\
\hline Tuerlersee & 0.01 & 0.44 & 7 & Matzinger et al. [2010] \\
\hline Onondaga & 0.07 & 1.68 & 8 & Matthews and Effler [2006] \\
\hline Truite & 0.02 & 0.16 & 3 & Cornett and Rigler [1987] \\
\hline
\end{tabular}

weaker daily winds that drive Poincaré waves have a negative effect on the rate of oxygen depletion in Lake Erie by thinning the diffusive sublayer and by increasing the flux through the sediment more than they increase the flux through the thermocline.

\subsection{Implications to Climate Change}

[42] Although this study did not focus explicitly on the consequence of DO depletion in the context of climate change, we believe that this work provides some useful perspectives. Recent models [Angel and Kunkel, 2010; Cheng et al., 2012] forecast a decrease in the water levels in the Great Lakes region by $0.5-1.5 \mathrm{~m}$, early stratification (e.g., less ice during winter), and an increase of strong daily wind events at the end of the century. The consequences of those three predictions were investigated in this study. Specifically, we showed that (1) a decrease of $1.5 \mathrm{~m}$ of the water level will increase the oxygen depletion by up to $10 \%$ (section 4.4); (2) an early stratification as observed in 2009 also has a negative effect on oxygen depletion (section 3.1 and Figure 5); and (3) energized daily wind will strengthen the Poincaré wave activity, which will thin the diffusive boundary layer and increase the SOD and the rate of oxygen depletion in the hypolimnion (section 3.5). Our observations suggest that the beneficial effects to water quality related to reductions in phosphorus loading reduction may be offset by the change in the external physical forcing predicted by these models.

\subsection{Implications to Other Lakes}

[43] Hypolimnion thickness appears to be an important parameter driving the rate of oxygen depletion by controlling the vertical volumetric fluxes of oxygen. Assuming that an averaged SOD value can be inferred from shorttime scale study and that the community respiration varies little over short-time scale, the ratio between vertical fluxes and the community respiration will be influenced primarily by the hypolimnion thickness in shallow lakes. Figure $11 \mathrm{~b}$ presents the results from the limited number of studies (seven lakes ranging in hypolimnion thickness from 3 to 85 $\mathrm{m}$; Table 3) that have quantified SOD:HOD in the field at seasonal time scales. These data reveal that the relative contribution of SOD to oxygen depletion decreases with lake depth. There is a good agreement between the line of best fit through these data and the predicted relative contribution of SOD from our Lake Erie measurements. This would support our conclusion that hypolimnion thickness is critical to the prediction of oxygen depletion in lakes. The onset of hypoxia or anoxia, based on the initial DO at the onset of the stratification, can be predicted in deep lakes where oxygen depletion is controlled by HOD. The situation is, however, more complicated in a shallow basin where the oxygen depletion is largely controlled by the SOD. Although the difference in the rate of oxygen depletion between lakes and reservoirs of varying depth can be explained primarily by the hypolimnion thickness (Figure $11 \mathrm{~b}$ ), a more detailed study including lakes of similar depth would be of particular interest to assess and ultimately parameterize the impact of external forcing such as wind energy and heat. We expect, for example, that the 4- to 5-m $\mathrm{s}^{-1}$ averaged wind speed we recorded on Lake Erie would increase the rate of oxygen depletion (through a deepening of the thermocline and a sustained energetic flow over the bottom increasing SOD) compared to other lakes of similar depth but weaker external forcing.

[44] Acknowledgments. The authors thank Gabriel Smith, Joey Battaglia, Peter Blouw, Reza Valipour, Serghei Bocaniov, and the crews of Limnos and Keenosay for their help in the field and laboratory. The authors are indebted to Yerubandi R. Rao (National Water Research Institute) for providing some data and logistical help. They also thank the three anonymous reviewers for their valuable comments. This research was supported by NSERC through a Strategic Project Grant (350475), and a Discovery Grant to J.D.A. Environment Canada and the Ontario Ministry of Natural Resources provided ship time, and some field equipment were funded by NSERC RTI to J.D.A. and L.B. and CFI/IOF grants to L.B.

\section{References}

Ackerman, J. D., M. R. Loewen, and P. F. Hamblin (2001), Benthic-Pelagic coupling over a zebra mussel reef in western Lake Erie, Limnol. Oceanogr., 46, 892-904.

Angel, J. R., and K. E. Kunkel (2010), The response of Great Lakes water levels to future climate scenarios with an emphasis on Lake MichiganHuron, J. Great Lakes Res., 36, 51-58.

Austin, J., and S. Colman (2008), A century of temperature variability in Lake Superior, Limnol. Oceanogr., 53, 2724-2730.

Beletsky, D., J. H. Saylor, and D. J. Schwab (1999), Mean circulation in the Great Lakes, J. Great Lakes Res., 25, 78-93.

Beletsky, D., N. Hawley, Y. R. Rao, H. A. Vanderploeg, R. Beletsky, D. J. Schwab, and S. A. Ruberg (2012), Summer thermal structure and anticyclonic circulation of Lake Erie, Geophys. Res. Lett., 39, doi:10.1029/ 2012GL051002.

Beutel, M., I. Hannoun, J. Pasek, and P. K. B. Kavanagh (2007), Evaluation of hypolimnetic oxygen demand in a large eutrophic raw water reservoir, San Vicente Reservoir, Calif, J. Environ. Eng., 133, 130-138.

Boegman, L., M. Loewen, P. Hamblin, and D. Culver (2008), Vertical mixing and weak stratification over zebra mussel colonies in western Lake Erie, Limnol. Oceanogr., 53, 1093-1110.

Bouffard, D., L. Boegman, and Y. R. Rao (2012), Poincare wave-induced mixing in a large lake, Limnol. Oceanogr., 57, 1201-1216.

Burns, N. M. (1976), Temperature, oxygen, and nutrient distribution patterns in Lake Erie, 1970, J. Fish. Res. Board Can., 33, 485-511.

Burns, N. M., D. C. Rockwell, P. E. Bertram, D. M. Dolan, and J. J. H. Ciborowski (2005), Trends in temperature, Secchi depth, and dissolved oxygen depletion rates in the central basin of Lake Erie, 1983-2002, J. Great Lakes Res., 31, 35-49. 
Chapra, S. C., and R. P. Canale (1991), Long-term phenomenolological model of phosphorus and oxygen for stratified lakes, Water Res., 25, 707-715.

Charlton, M. N. (1980), Hypolimnion oxygen consumption in lakes: Discussion of productivity and morphometry effects, Can. J. Fish. Aquat. Sci., 37, 1531-1539.

Charlton, M. N. (1987), Lake Erie oxygen revisited, J. Great Lakes Res., 13, 697-708.

Charlton, M. N., and D. R. S. Lean (1987), Sedimentation, resuspension, and oxygen depletion in Lake Erie (1979), J. Great Lakes Res., 13, 709723.

Charlton, M. N., and J. E. Milne (2004), Review of thirty years of change in Lake Erie water quality, NWRI Environment Canada Contribution No. 04-167, Environment Canada, Burlington, Ont.

Cheng, C. S., H. Auld, Q. Li, and G. Li (2012), Possible impacts of climate change on extreme weather events at local scale in south-central Canada, Clim. Change, 112, 963-979.

Conroy, J. D., L. Boegman, H. Zhang, W. J. Edwards, and D. A. Culver (2010), "Dead zone" dynamics in Lake Erie: The importance of weather and sampling intensity for calculated hypolimnetic oxygen depletion rates, Aquat. Sci., 73, 289-304.

Cornett, R. J., and F. H. Rigler (1987), Decomposition of Seston in the hyolimnion, Can. J. Fish. Aquat. Sci., 44, 146-151.

Diaz, R. J., and R. Rosenberg (2008), Spreading dead zones and consequences for marine ecosystems, Science, 321, 926-929.

Edwards, W. J., J. D. Conroy, and D. A. Culver (2005), Hypolimnetic oxygen depletion dynamics in the central basin of Lake Erie, J. Great Lakes Res., 31, 262-271.

Fee, E. J. (1976), The vertical and seasonal distribution of chlorophyll in lakes of the Experimental Lakes Area, northwestern Ontario: Implications for primary production estimates, Limnol. Oceanogr., 21, 767-783.

Hawley, N., T. Johengen, Y. Rao, and S. Ruberg (2006), Lake Erie hypoxia prompts Canada-US study, Eos Trans. AGU, 87, 2005-2007, doi:10.1029/2006EO320001.

Hondzo, M. (1998), Dissolved oxygen transfer at the sediment-water interface in a turbulent flow, Water Resour. Res., 34, 3525-3533.

Kemp, A. L. W., G. A. MacInnis, and N. S. Harper (1977), Sedimentation rates and a revised sediment budget for Lake Erie, J. Great Lakes Res., 3, 221-233.

Lam, D. C. L., W. M. Schertzer, and A. S. Fraser (1987), Oxygen depletion in Lake Erie: Modeling the physical, chemical, and biological interactions, 1972 and 1979, J. Great Lakes Res., 13, 770-781.

Lee, J. H. W., C. P. Kuang, and K. S. Yung (2000), Fluid mechanics of triangular sediment oxygen demand chamber, J. Environ. Eng., 126, 208 216.

León, L. F., J. Imberger, R. E. H. Smith, R. E. Hecky, D. C. L. Lam, and W. M. Schertzer (2005), Modeling as a tool for nutrient management in Lake Erie: A hydrodynamics study, J. Great Lakes Res., 31, 309-318.

Loewen, M. R., J. D. Ackerman, and P. F. Hamblin (2007), Environmental implications of stratification and turbulent mixing in a shallow lake basin, Can. J. Fish. Aquat. Sci., 64, 43-57.

Lorke, A. (2007), Boundary mixing in the thermocline of a large lake, $J$. Geophys. Res., 112, C09019, doi:10.1029/2006JC004008.

Lorke, A., L. Umlauf, and T. Jonas (2002), Dynamics of turbulence in lowspeed oscillating bottom-boundary layers of stratified basins, Environ. Fluid Mech., 2, 291-313.

Lorke, A., B. Muller, M. Maerki, and A. Wuest (2003), Breathing sediments: The control of diffusive transport across the sediment-water interface by periodic boundary-layer turbulence, Limnol. Oceanogr., 48, 2077-2085.
Lozovatsky, I. D., E. Roget, H. J. S. Fernando, M. Figueroa, and S. Shapovalov (2006), Sheared turbulence in a weakly stratified upper ocean, Deep Sea Res., 53, 387-407.

Matisoff, G., and J. J. H. Ciborowski (2005), Lake Erie trophic status collaborative study, J. Great Lakes Res., 31, 1-10.

Matisoff, G., and T. M. Neeson (2005), Oxygen concentration and demand in Lake Erie sediments, J. Great Lakes Res., 31, 284-295.

Matthews, D. A., and S. W. Effler (2006), Long-term changes in the areal hypolimnetic oxygen deficit (AHOD) of Onondaga Lake: Evidence of sediment feedback, Limnol. Oceanogr., 51, 702-714.

Matzinger, A., B. Muller, P. Niederhauser, M. Schmid, and A. Wuest (2010), Hypolimnetic oxygen consumption by sediment-based reduced substances in former eutrophic lakes, Limnol. Oceanogr., 55, 2073-2084.

Molot, L. A., P. J. Dillon, B. J. Clark, and B. P. Neary (1992), Predicting end-of-summer oxygen profiles in stratified lakes, Can. J. Fish. Aquat. Sci., 49, 2363-2372.

Mortimer, C. (1987), Fifty years of physical investigations and related limnological studies on Lake Erie, 1928-1977, J. Great Lakes Res., 13, 407-435.

Polzin, K. (1996), Statistics of the Richardson number: Mixing models and fine structure, J. Phys. Oceanogr., 26, 1409-1425.

Rabalais, N. N., R. E. Turner, and W. J. Wiseman Jr. (2002), Gulf of Mexico hypoxia, aka "the dead zone", Annu. Rev. Ecol. Syst., 33, 235-263.

Rao, Y. R., N. Hawley, M. N. Charlton, and W. M. Schertzer (2008), Physical processes and hypoxia in the central basin of Lake Erie, Limnol. Oceanogr., 53, 2007-2020.

Rosa, F., and N. M. Burns (1987), Lake Erie central basin oxygen depletion changes from 1929-1980, J. Great Lakes Res., 13, 684-696.

Rucinski, D. K., D. Beletsky, J. V. DePinto, D. J. Schwab, and D. Scavia (2010), A simple 1-dimensional, climate based dissolved oxygen model for the central basin of Lake Erie, J. Great Lakes Res., 36, 465-476.

Saylor, J. H., and G. S. Miller (1987), Studies of large-scale currents in Lake Erie, 1979-80, J. Great Lakes Res., 13, 487-514.

Scalo, C., U. Piomelli, and L. Boegman (2012), High-Schmidt-number mass transport mechanisms from a turbulent flow to absorbing sediments, Phys. Fluids, 24, 085103.

Schertzer, W. (1987), Heat balance and heat storage estimates for Lake Erie, 1967 to 1982, J. Great Lakes Res., 13, 454-467.

Smith, D. A., and G. Matisoff (2008), Sediment oxygen demand in the central basin of Lake Erie, J. Great Lakes Res., 34, 731-744.

Snodgrass, W. J. (1987), Analysis of models and measurements for sediment oxygen demand in Lake Erie, J. Great Lakes Res., 13, 738-756.

Snodgrass, W. J., and L. A. Fay (1987), Values of sediment oxygen demand measured in the central basin of Lake Erie, 1979, J. Great Lakes Res., 13, $724-730$.

Valipour, R. (2012), Basin-scale waves dynamics and sediment resuspension mechanics in central Lake Erie, Ph.D. thesis, 124 pp., Queen's Univ., Kingston, Ont., Canada.

Viollier, E., A. Groleau, B. Deflandre, D. Jezequel, G. Sarazin, and C. Rabouille (2007), Benthic oxygen demand and hypolimnion anoxia in a great lake, Bourget lake, France, paper presented at the Aquatic Science Meeting, ASLO, Santa Fe, N. M.

Weiss, R. (1970), The solubility of nitrogen, oxygen and argon in water and seawater, Deep Sea Res., 17, 721-735.

Wiles, P. J., T. P. Rippeth, J. H. Simpson, and P. J. Hendricks (2006), A novel technique for measuring the rate of turbulent dissipation in the marine environment, Geophys. Res. Lett., 33, L21608, doi:10.1029/ 2006GL027050.

Wüest, A., and A. Lorke (2003), Small-scale hydrodynamics in lakes, Annu. Rev. Fluid Mech., 35, 373-412. 